Effects of Trade on Female Labor Force Participation Philip Sauré and Hosny Zoabi

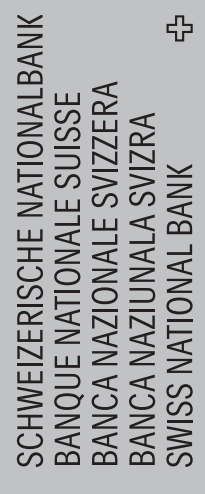

U

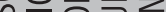

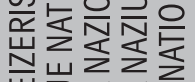

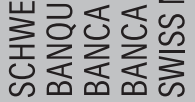

?

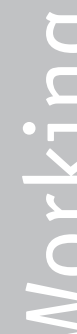


The views expressed in this paper are those of the author(s) and do not necessarily represent those of the Swiss National Bank. Working Papers describe research in progress. Their aim is to elicit comments and to further debate.

\section{Copyright ${ }^{\odot}$}

The Swiss National Bank (SNB) respects all third-party rights, in particular rights relating to works protected by copyright (information or data, wordings and depictions, to the extent that these are of an individual character). SNB publications containing a reference to a copyright ( $\odot$ Swiss National Bank/SNB, Zurich/year, or similar) may, under copyright law, only be used (reproduced, used via the internet, etc.) for non-commercial purposes and provided that the source is mentioned. Their use for commercial purposes is only permitted with the prior express consent of the SNB.

General information and data published without reference to a copyright may be used without mentioning the source.

To the extent that the information and data clearly derive from outside sources, the users of such information and data are obliged to respect any existing copyrights and to obtain the right of use from the relevant outside source themselves.

\section{Limitation of liability}

The SNB accepts no responsibility for any information it provides. Under no circumstances will it accept any liability for losses or damage which may result from the use of such information. This limitation of liability applies, in particular, to the topicality, accuracy, validity and availability of the information.

ISSN 1660-7716 (printed version)

ISSN 1660-7724 (online version)

๑ 2009 by Swiss National Bank, Börsenstrasse 15, P.0. Box, CH-8022 Zurich 


\title{
Effects of Trade on Female Labor Force Participation*
}

\author{
Philip Sauré Hosny Zoabi $^{\ddagger}$
}

\begin{abstract}
Male and female labor are imperfect substitutes and some sectors are more suitable for female employment than others. Clearly, expansions of those sectors that use female labor intensively must affect aggregate female labor force participation (FLFP). We suggest that FLFP actually drops when trade and international specialization expand sectors that use female labor intensively. This effect arises because expansions of the former sectors come along with contractions of others. The latter contractions, in turn, induce male workers to move to the expanding sectors, driving female workers out of formal employment. Thus, a country that is exporting female labor content is actually substituting male labor for female. Finally, building on U.S.-Mexican trade data, we provide empirical evidence that support our argument.
\end{abstract}

Keywords: Trade, Female Labor Force Participation, Fertility, Technological Change. JEL Classifications: F10, F16, J13, J16.

\footnotetext{
*We would like to thank Daron Acemoglu, Raphael Auer, David de la Croix, Matthias Doepke, Oded Galor, Moshe Hazan, Elhanan Helpman, Kiminori Matsuyama, Omer Moav, Joel Mokyr, Yona Rubinstein, Analia Schlosser, David Weil and Joseph Zeira and two anonymous referees for valuable comments. All remaining errors are ours. All remaining errors are ours. The views expressed in this paper are the author's and do not necessarily represent those of the Swiss National Bank.

${ }^{\dagger}$ P. Sauré, Swiss National Bank, Boersenstrasse 15, CH-8022 Zurich, Switzerland. E-mail: Philip.Saure@snb.ch.

${ }^{\ddagger}$ H. Zoabi, The Eitan Berglas School of Economics, Tel Aviv University, P.O.B. 39040 Ramat Aviv, Tel Aviv 69978, Israel. E-mail: hosnyz@post.tau.ac.il.
} 


\section{Introduction}

World trade volumes have increased secularly during the last century. From 1870 to 1998 growth in world trade has quadrupled growth in world income (Maddison (2001)). Another significant feature of the twentieth century was the increase in female labor force participation. The participation of married women in the U.S. labor market has been increasing from around $2 \%$ in 1880 to over $70 \%$ in 2000 (Fernández (2007)).

The focus of this study is to understand channels through which two major economic factors, international trade and female labor force participation, are linked. Our main concern is to show how differences in capital labor ratios across economies, via international specialization, affect the trade-off in household decisions between fertility and female labor force participation and how these decisions, in turn, feed back on growth rates of per household capital stocks.

Our theory relies on an assumption concerning labor supply that is consistent with empirical regularities: male workers have relative advantage in brawn intensive tasks and female workers have relative advantage in brain intensive tasks. More precisely, we assume that females and males have equal quantities of brains, but males have more brawn. As a direct consequence, males' wages are higher than females' wages as long as brawn is a valued input. ${ }^{1}$ Indeed, Figure 1 shows that the wage ratio between female workers and male workers in the U.S. is less than one during the period 1800-1990.

Assumptions two and three characterize the labor demand of our model. Thus, childrearing is assumed to require time that cannot be spent working so that the opportunity cost of raising children is proportional to the market wage. ${ }^{2}$ Therefore, given that males and females are equally productive in raising children, women with the lower market wage raise children.

\footnotetext{
${ }^{1}$ O'Neill (2003) shows that there is still a 10 differential in female and male wages in the U.S. in 2000, that is still unexplained by gender differences in schooling, actual experience and job characteristics.

${ }^{2}$ Goldin (1995) provides evidence that shows that few women in the 1940's and 1950's birth cohorts were able to combine childbearing with strong labor-force attachment. Angrist and Evans (1998) and Bailey (2006) find a negative causal effect running from fertility to female labor force participation.
} 
According to our third assumption physical capital complements brains more than brawn. In combination with the difference in endowments of brains and brawn between male and female workers, the last assumption implies that male labor and female labor are imperfect substitutes. $^{3}$ Moreover, as economies accumulate physical capital, the rewards to brains increase relative to brawn and the gender wage gap declines. Indeed, Goldin (1990) writes:

The labor market's rewards for strength, which made up a large fraction of earnings in the nineteenth century, ought to be minimized by the adoption of machinery, and its rewards for brain power ought to be increased ( $p .59)$.

To formalize our three assumptions, we adopt the model of Galor and Weil (1996) and generalize it to a trade setting. Based on the intrinsic differences in labor endowments between the sexes we distinguish between a brain intensive sector, which we label "females' relative advantage sector" (FRAS) and a brawn intensive sector, or "males' relative advantage sector" (MRAS).

Within this framework, we analyze how female labor force participation is affected by an expansion or a contraction in a sector that intensively uses female labor. As a result of international trade, some economies specialize in FRAS, which expands on the expense of MRAS, while the opposite pattern displays in other economies. Interestingly, our theory suggests that expanding FRAS hinders female labor force participation, while expanding MRAS generates the mirror image.

The intuition of this seemingly paradoxical result runs along the following lines. First, men have higher wages and, therefore, are always formally employed. Second, when an economy specializes on the FRAS, the MRAS contracts and male workers move to the FRAS sector. Third, the inflow of male workers to the FRAS, depresses the capital-labor ratio in this sector. Thus, given the relatively strong complementarity between physical capital and

\footnotetext{
${ }^{3}$ Acemoglu, Autor and Lyle (2004) have utilized the large positive shock to demand for female labor induced by World War II to understand the effect of an increase in female labor supply on females' and males' wages. They find that a $10 \%$ increase in female labor input decreases females' wages by about $7 \%-8 \%$, but reduces males' wages by only $3 \%-5 \%$. This suggests that the elasticity of substitution between female and male labor ranges between 2.5 and 3.5 .
} 
brains, the marginal productivity of brains drops by more than the marginal productivity of brawn, consequently increasing the wage gap. Finally, the increase in the wage gap depresses female labor force participation.

Simplifying this mechanism, it can be said that, by moving from MRAS to FRAS, male workers "drive female workers out" of formal employment. Conversely, under specialization on the MRAS, male workers withdraw from FRAS, which "opens job opportunities" for women and fosters female labor force participation.

Our mechanism also applies in the case of technological progress, which is biased towards female labor. In particular, technological progress biased towards FRAS increases the wages in this sector. This increase in wages attracts male workers who leave the MRAS, an effect that can be strong enough to drive female workers out of formal employment. In this way, technological progress biased towards female labor might curb female labor force participation. $^{4}$

The dynamics of our two-country model are affected by three basic elements from trade and demographic theory. First, in a Heckscher-Ohlin framework, the relative endowments of production factors, physical capital, and labor, determine specialization patterns. Second, specialization patterns affect the gender wage gap. Third, the gender wage gap affects household choice of female labor force participation and fertility. These choices, in turn, impact household savings and population growth, which, finally, determine the per-household capital stock for the subsequent generation. Adding the complementarity assumption between physical capital and female labor described above, it is the capital abundant economy which specializes in the FRAS and vice versa.

Thus, our model suggests that international trade enhances growth of per-household capital in the capital scarce economy by fostering its female labor share and decreasing its fertility rates at the same time. The impact of trade on the capital abundant economy,

\footnotetext{
${ }^{4}$ For the role of technological progress in explaining the demographic transition see Galor and Weil ((1999), (2000)) and Galor and Moav (2002). For the impact of technological progress on fertility and female labor force participation see Greenwood and Seshadri (2005) and Doepke, Hazan and Maoz (2007).
} 
however, is ambiguous. While international trade hinders female labor force participation and increases fertility, these adverse effects on per-household capital accumulation may or may not be dominated by the positive effects through the gains from trade. In either case, our model suggests that trade cannot accelerate capital accumulation in the rich country by more than it accelerates it in the poor country and, thus, our theory predicts convergence of per-household capital stocks.

The model connects to various strands in the literature. The work connecting international trade and labor markets typically analyzes the impact of trade on unemployment and labor reallocation (e.g., Davis (1998), Wacziarg and Wallack (2004) and Helpman and Itskhoki (2007)). Related articles reveal labor market friction as a determinant of comparative advantage and international trade (Saint-Paul (1997), Cunat and Melitz (2007)). Other scholars investigate whether to include labor market standards in trade agreements (Brown (2001) and Bagwell and Staiger (2001)). The link between trade, the gender wage gap and female labor force participation, however, is understudied. A noteworthy exception is Becker (1957) who argues that trade increases competition among firms and, thus, reduces costly discrimination and closes the gender wage gap. Tests of this hypothesis have generally produced mixed support (see Black and Brainerd (2004), Hazarika and Otero (2004), Berik, van der Meulen and Zveglich (2004) for some of the scarce empirical investigations). Our mechanism, in contrast, operates through the differential demand for gender labor across sectors and international specialization under perfectly competitive goods and factor markets.

A different literature addresses the reduction in the gender wage gap and the increase in women's labor force participation has been the subject of much debate. Welch (2000), Gosling (2003) and Black and Spitz-Oener (2007) focus on the role of primary attributes. While Welch (2000) and Gosling (2003) attribute the reduction in the gender wage gap to the expansion in the value of brains relative to brawn, Black and Spitz-Oener (2007) addresses the importance of the relative increases in non-routine analytic tasks and non- 
routine interactive tasks, which are associated with higher skill levels. ${ }^{5}$ Our paper is close to this literature by taking primary attributes as the source of the gender wage gap.

The link between women's relative wages and fertility is fairly well established. ${ }^{6}$. In our framework, the pure effect of an increase in household income, holding the price of children constant, is to raise the demand for children. If all child-rearing are done by females, an increase in females' wages raises both household income and the price of children, and thus has offsetting income and substitution effects on the demand for children. ${ }^{7}$ In our model, if both males' and females' wages proportionately increase, then the substitution effect driven by the increase in the cost of raising children negates the income effect and leaves fertility unchanged. In such a framework, closing gender wage gap causes fertility to decline. ${ }^{8}$

There is little research on the links and interactions between demography and international trade. Closest to our argument is Galor and Mountford (2008) who endogenize educational choice and fertility choice, arguing that the gains from trade are channeled towards population growth in non-industrial countries while in industrial countries they are directed towards investment in education and growth in output per-capita. ${ }^{9}$ Our theory predicts the opposite effect: trade reduces fertility in developing countries and enhances capital accumulation and growth of income per-capita, simultaneously highlighting its impact on female labor force participation.

To advance our understanding of how trade affects female labor force participation quantitatively, we test our theory using bilateral trade data for the U.S. (the rich economy) and

\footnotetext{
${ }^{5}$ See also Mulligan and Rubinstein (2005) who attribute the reduction in the gender wage gap to a positive selectivity bias and Fernández (2007) who addresses the role of culture and learning. For gender wage gap in the U.S., see Goldin (1990) and for the evolution of female labor force participation, see Goldin (2006).

${ }^{6}$ The analysis of fertility in the context of relative wages dates back to Becker (1960) and Mincer (1963)

${ }^{7}$ Pencavel (1986) finds a positive association between fathers' labor supply and the number of children. This is consistent with our framework assuming that fathers' wage has a pure income effect on the number of children.

${ }^{8}$ For a comprehensive discussion on the demographic transition see Galor (2005).

${ }^{9}$ Their theory suggests that international trade enhanced the specialization of industrial economies in the production of skill intensive goods. The increase in demand for skilled labor induced an investment in the quality of the population, expediting demographic transition, stimulating technological progress and further enhancing the comparative advantage of these industrial economies in the production of skill intensive goods. Thus, the pattern of trade enhances the initial pattern of comparative advantages and disadvantages.
} 
Mexico (the poor economy). Central to our estimation strategy is the observation that the surge in bilateral trade volumes over the period 1990-2007 was uneven across the 51 U.S. states. For example, trade with Mexico increased by almost 3.2 percent of total output for Texas, while for New York the increase was 0.1 percent of total output. We exploit this crossstate variation in the exposure to trade with Mexico to examine how trade has impacted female labor force participation. Instrumenting trade shares with geographic distance, our cross-state regressions support the hypothesis that, in rich economies, international trade with poor countries tends to reduce female labor supply. These findings are robust to various definitions of female labor supply and a set of controls.

The rest of the paper is organized as follows. Section 2 formalizes our argument, section 3 provides an empirical evidence and section 4 presents some concluding remarks. Figures and tables appear at the end.

\section{The Model}

In our modeling strategy we follow Galor and Weil (1996) by adopting a standard OLG model with endogenous choice of fertility.

At time $t$ the economy is populated by $L_{t}$ households, each containing one adult man (a husband) and one adult woman (a wife). Individuals live for three periods: childhood, adulthood and old age. In childhood, individuals consume a fixed quantity of their parents' time. In adulthood, individuals raise children, supply labor to the market, and save their wages. In old age, individuals merely consume their savings. The capital stock in each period is equal to the aggregate savings of the previous period.

A key assumption is that men and women differ in their labor endowments. While men and women have equal endowments of mental labor units, men have more physical labor units than women. These differences translate into a gender wage gap, which, in turn, governs the trade-off between female labor force participation and fertility. 


\subsection{Production}

\subsubsection{Technologies}

Two intermediate goods, $X_{1}$ and $X_{2}$ are assembled into a final good $Y$ by the CES-technology:

$$
Y_{t}=\left(\theta X_{1, t}^{\rho}+(1-\theta) X_{2, t}^{\rho}\right)^{1 / \rho} \quad \rho, \theta \in(0,1)
$$

Intermediate goods are produced using three factors: capital $K$, physical labor $L^{p}$, and mental labor $L^{m}$. We want to reflect the fact that sectors vary in their factor intensity, in particular, in their intensity of mental and physical labor. This, in turn, generates differences in demand for male and female labor across sectors. Thus, we impose the following structure on production of intermediate goods ${ }^{10}$

$$
\begin{aligned}
& X_{1}=a K_{t}^{\alpha}\left(L_{t}^{m}\right)^{1-\alpha}+b L_{1, t}^{p} \\
& X_{2}=b L_{2, t}^{p} .
\end{aligned}
$$

Here, the variables $L_{i, t}^{p}$ stand for the physical labor employed in sector $i$ at time $t$, while $L_{t}^{m}$ is the amount of mental labor in the first sector at time $t$.

\subsubsection{Labor Supply}

Men and women are equally efficient in raising children. On the labor market, however, each woman supplies one unit of mental labor $L^{m}$ while men supply one unit of mental labor $L^{m}$ plus one unit of physical labor $L^{p}$. Thus, as long as physical labor has a positive price, men receive a higher wage than women and therefore the opportunity cost of raising children is higher for a man than for a woman. Consequently, men only raise children when women are doing so full-time. Finally, we assume that male workers cannot divide mental and physical labor and must allocate both units to one sector. This means, in particular,

\footnotetext{
${ }^{10}$ As shown in an earlier version of this paper, assuming that physical capital is a production factor of $X_{2}$ does not change the spirit of our results.
} 
that men employed in the $X_{2}$-sector waste their mental endowment.

\section{$2.2 \quad$ Preferences}

Individuals born at $t-1$ form households in period $t$ and derive utility from the number of their children $n_{t}$ and their joint old-age consumption $c_{t+1}$ of a final good $Y$ according to ${ }^{11}$

$$
u_{t}=\gamma \ln \left(n_{t}\right)+(1-\gamma) \ln \left(c_{t+1}\right)
$$

It is assumed that parents' time is the only input required to raise children and thus the opportunity cost of raising children is proportional to the market wage. Let $w_{t}^{F}$ and $w_{t}^{M}$ be the hourly wage of female and male workers, respectively. Normalizing the hours per period to unity, the full income of a household is $w_{t}^{M}+w_{t}^{F}$, which is spent on consumption and raising children. Further, let $z$ be the fraction of the time endowment of one parent that must be spent to raise one child. If the wife spends time raising children, then the marginal cost of a child is $z w_{t}^{F}$. If the husband spends time raising children, then the marginal cost of a child is $z w_{t}^{M}$. The household's budget constraint is therefore

$$
\begin{aligned}
& w_{t}^{F} z n_{t}+s_{t} \leq w_{t}^{M}+w_{t}^{F} \quad \text { if } \quad z n_{t} \leq 1 \\
& w_{t}^{F}+w_{t}^{M}\left(z n_{t}-1\right)+s_{t} \leq w_{t}^{M}+w_{t}^{F} \quad \text { if } \quad z n_{t} \geq 1
\end{aligned}
$$

where $s_{t}$ is the household's savings. In the third period, the household consumes their savings

$$
c_{t+1}=s_{t}\left(1+r_{t+1}\right)
$$

where $r_{t+1}$ is the net real interest rate on savings.

\footnotetext{
${ }^{11}$ Note that since the basic unit is a household which consists a husband and wife, $n_{t}$ is, in fact, the number of pairs of children that a couple has.
} 


\subsection{Optimality}

It will prove useful to conduct the analysis in terms of per-household variables. We therefore define:

$$
k_{t}=K_{t} / L_{t} \quad m_{t}=L_{t}^{m} / L_{t} \quad l_{i, t}=L_{i, t}^{p} / L_{t}
$$

as capital, productive mental labor and sectorial physical labor per-household, respectively. Finally, we define

$$
\kappa_{t}=k_{t} / m_{t}
$$

as the ratio of capital to mental labor employed in the first sector. This ratio will play a central role in the following analysis.

\subsubsection{Firms}

Profit maximization of decentralized intermediate goods firms implies, by (2), that relative prices are:

$$
\frac{p_{2, t}}{p_{1, t}}=\frac{1-\theta}{\theta}\left(\frac{X_{1}}{X_{2}}\right)^{1-\rho}=\frac{1-\theta}{\theta}\left(\frac{a \kappa_{t}^{\alpha} m_{t}+b l_{1, t}}{b l_{2, t}}\right)^{1-\rho},
$$

where we write $p_{i, t}$ as $X_{i}$ 's price in period $t$. Given $p_{i, t}$, cost minimizing final good producers leads us to the usual ideal price index $P_{t}$, which we normalize to one

$$
P_{t}=\left(\left(\frac{\theta}{p_{1, t}^{\rho}}\right)^{1 /(1-\rho)}+\left(\frac{1-\theta}{p_{2, t}^{\rho}}\right)^{1 /(1-\rho)}\right)^{-(1-\rho) / \rho}=1 .
$$

From equation (2) the return to capital in the first sector is

$$
r_{t}=p_{1, t} \alpha a \kappa_{t}^{\alpha-1}
$$


Wages are derived from (2) and reflect the marginal productivity of labor. For males we have

$$
\begin{array}{lll}
w_{t}^{M}=p_{1, t} b\left[(1-\alpha) a / b \kappa_{t}^{\alpha}+1\right] & \text { if } & L_{1, t}^{p}>0 \\
w_{t}^{M}=p_{2, t} b & \text { if } & L_{2, t}^{p}>0,
\end{array}
$$

which reflects mental and physical labor productivity in the first sector, and only physical labor productivity in the second sector. Similarly, female wage is

$$
w_{t}^{F}=p_{1, t}(1-\alpha) a \kappa_{t}^{\alpha} \quad \text { if } \quad z n_{t}<1
$$

which reflects mental labor productivity in the first sector.

\subsubsection{Households}

Household's maximizing problem yields

$$
z n_{t}= \begin{cases}\gamma\left(1+w_{t}^{M} / w_{t}^{F}\right) & \text { if } \quad \gamma\left(1+w_{t}^{M} / w_{t}^{F}\right) \leq 1 \\ 2 \gamma & \text { if } \quad 2 \gamma \geq 1 \\ 1 & \text { otherwise. }\end{cases}
$$

Equation (13) implies that in the case in which $\gamma \geq 1 / 2$ women raise children full time regardless of their wages. We rule out this scenario by imposing $\gamma<1 / 2$. Under this restriction, women raise children full-time only under very high gender wage gaps. But as the gender gap decreases women join the labor force and fertility decreases. When $w_{t}^{F}$ approaches $w_{t}^{M}$, women spend a fraction $2 \gamma$ of their time raising children. Finally, under $\gamma<1 / 2$ the budget constraint (4) collapses to

$$
s_{t}=\left(1-z n_{t}\right) w_{t}^{F}+w_{t}^{M}
$$


and (13) becomes

$$
z n_{t}=\min \left\{\gamma\left(1+w_{t}^{M} / w_{t}^{F}\right), 1\right\}
$$

\subsection{Closed Economy}

\subsubsection{Static Equilibrium}

The equilibrium of the integrated economy is determined by looking at two regimes separately. The first is a regime in which women do not participate in the formal labor market, and the second is a regime in which women participate. To simplify the analysis, we assume that, in equilibrium, the second sector is too small to accommodate all male labor. Specifically, we assume ${ }^{12}$

$$
2-\alpha \geq 1 / \theta
$$

to be satisfied throughout the following analysis. Under this assumption, $L_{1, t}^{p}>0$ holds and the ratio of male to female wage can be computed by the marginal productivities in the first sector

$$
\frac{w^{M}}{w^{F}}=1+\frac{b}{(1-\alpha) a \kappa_{t}^{\alpha}} .
$$

This ratio determines female labor force participation $1-z n_{t}$ through (15)

$$
z n_{t}=\min \left\{\gamma\left(2+\frac{b}{(1-\alpha) a \kappa_{t}^{\alpha}}\right), 1\right\}
$$

To determine equilibrium $\kappa_{t}$, combine male wages (10) and (11), prices (7), and the resource constraint for male labor $1=l_{1, t}+l_{2, t}$ to get

$$
(1-\alpha) \frac{a}{b} \kappa_{t}^{\alpha}+1=\frac{1-\theta}{\theta}\left(\frac{\frac{a}{b} \kappa_{t}^{\alpha} m_{t}+l_{1, t}}{1-l_{1, t}}\right)^{1-\rho} .
$$

\footnotetext{
${ }^{12} \mathrm{~A}$ sufficient condition for $l_{i, t}>0$ is that the relative price (7) falls short of the ratio of marginal rates of transformation at $l_{1, t}=0$ and $z n_{t}=0$ i.e. $(1-\alpha) \kappa_{t}^{\alpha} a / b+1>(1-\theta) / \theta\left(\kappa_{t}^{\alpha} a / b\right)^{1-\rho}$. If $\kappa_{t}^{\alpha} a / b \geq 1$ then this sufficient condition is implied by $(1-\alpha) \geq(1-\theta) / \theta$, or (16). If $\kappa_{t}^{\alpha} a / b<1$ instead, the sufficient condition is implied by $1>(1-\theta) / \theta$ and hence, again, by (16).
} 
Further note that

$$
l_{1, t}=m_{t}-\left(1-z n_{t}\right)
$$

so that equation (19) becomes

$$
(1-\alpha) \frac{a}{b} \kappa_{t}^{\alpha}+1=\frac{1-\theta}{\theta}\left(\frac{\frac{a}{b} \kappa_{t}^{\alpha} m_{t}+m_{t}-\left(1-z n_{t}\right)}{1-m_{t}+\left(1-z n_{t}\right)}\right)^{1-\rho}
$$

Equations (6), (18), and (21) determine $m_{t}$ and $z n_{t}$ and thus the equilibrium. There are two qualitatively different types of equilibria to distinguish.

The First Regime $z n_{t}=1$. In the case in which $z n_{t}=1$, equation (21) can be written in terms of $\kappa_{t}$ (substitute $\left.m_{t}=k_{t} / \kappa_{t}\right)$ :

$$
(1-\alpha) \frac{a}{b} \kappa_{t}^{\alpha}+1=\frac{1-\theta}{\theta}\left(\frac{\frac{a}{b} \frac{k_{t}}{\kappa_{t}^{1-\alpha}}+\frac{k_{t}}{\kappa_{t}}}{1-\frac{k_{t}}{\kappa_{t}}}\right)^{1-\rho}
$$

The Second Regime $z n_{t}<1$. In case in which $z n_{t}<1$ we use $m_{t}=k_{t} / \kappa_{t}$ and $z n_{t}$ from (18) to write $(21)$ as

$$
(1-\alpha) \frac{a}{b} \kappa_{t}^{\alpha}+1=\frac{1-\theta}{\theta}\left(\frac{\frac{a}{b} \frac{k_{t}}{\kappa_{t}^{1-\alpha}}+\frac{k_{t}}{\kappa_{t}}-1+\gamma\left(2+\frac{b}{a} \frac{\kappa_{t}^{-\alpha}}{1-\alpha}\right)}{1-\frac{k_{t}}{\kappa_{t}}+1-\gamma\left(2+\frac{b}{a} \frac{\kappa_{t}^{-\alpha}}{1-\alpha}\right)}\right)^{1-\rho}
$$

Equations (22) and (23) determine the equilibrium $\kappa_{t}$ in the first and second regime, respectively. Notice that expressions on the left of both equations are increasing in $\kappa_{t}$, while both terms on the right are decreasing in $\kappa_{t}$. This implies that $\kappa_{t}$ is unique in both regimes. Moreover, the expressions on the right of (22) and (23) are increasing in $k_{t}$ and we can write $\kappa_{t}\left(k_{t}\right)$ as an increasing function.

This means that, quite intuitively, a capital-rich economy has a higher capital-mental labor share than a capital scarce economy. When going back to equation (18), this observation shows also that the higher the capital stock $k_{t}$ of an economy, the lower fertility $z n_{t}$ is. As $\left.\kappa_{t}\left(k_{t}\right)\right|_{k_{t}=0}=0,(18)$ further implies that there is a $k_{o}>0$ so that the economy is in 
the first regime when its capital stock falls short of $k_{o}$, while the economy is in the second regime if not. By combining condition $\gamma\left(2+b /\left[(1-\alpha) a \kappa_{o}^{\alpha}\right]\right)=1$ with equation (22) and $\kappa_{o}=k_{o} / m_{o}$, this threshold can be shown to be

$$
k_{o}=\theta(1-\gamma)\left(1-2 \gamma+\gamma \frac{1-\alpha \theta}{1-\alpha}\right)^{-1}\left[\frac{(1-\alpha)(1-2 \gamma)}{\gamma} \frac{a}{b}\right]^{-1 / \alpha}
$$

At capital stocks below the threshold $k_{o}$ all women raise children full-time. When capital is gradually accumulated and this threshold is passed, women integrate into the labor market and, as the variable $\kappa_{t}$ keeps increasing, the gender wage gap closes and female labor supply rises. At the same time, and as a mirror image, fertility declines.

These observations regarding the impact of the capital stock on fertility and on female labor force participation bring us to the dynamics of the model.

\subsubsection{Dynamics}

The dynamics of the model are governed by two endogenous variables: savings $s_{t}$ and fertility $n_{t}$. With the notation in per-household terms, the ratio of saving and fertility gives the next period's capital stock, i.e. $k_{t+1}=s_{t} / n_{t}$. Combining the budget constraint (14) and fertility (15) and distinguishing the two regimes, we can write

$$
k_{t+1}=\frac{s_{t}}{n_{t}}= \begin{cases}z w_{t}^{M} & \text { if } k_{t}<k_{o} \\ z \frac{1-\gamma}{\gamma} w_{t}^{F} & \text { if } \quad k_{t} \geq k_{o}\end{cases}
$$

Equations (10) and (11) give the price ratio

$$
\frac{p_{2, t}}{p_{1, t}}=(1-\alpha) \frac{a}{b} \kappa_{t}^{\alpha}+1
$$


which, combined with the normalization (8), renders the price of the first intermediate good

$$
p_{1, t}=\left(\theta^{1 /(1-\rho)}+(1-\theta)^{1 /(1-\rho)}\left(\frac{1}{(1-\alpha) \frac{a}{b} \kappa_{t}^{\alpha}+1}\right)^{\rho /(1-\rho)}\right)^{(1-\rho) / \rho} .
$$

With (10), (12) and (25) we thus have

$$
k_{t+1}=\left\{\begin{array}{cl}
z b\left(\theta^{\frac{1}{1-\rho}}\left((1-\alpha) \frac{a}{b} \kappa_{t}^{\alpha}+1\right)^{\frac{\rho}{1-\rho}}+(1-\theta)^{\frac{1}{1-\rho}}\right)^{\frac{1-\rho}{\rho}} & \text { if } \quad k_{t}<k_{o} \\
z b \frac{1-\gamma}{\gamma}\left(\theta^{\frac{1}{1-\rho}}\left((1-\alpha) \frac{a}{b} \kappa_{t}^{\alpha}\right)^{\frac{\rho}{1-\rho}}+(1-\theta)^{\frac{1}{1-\rho}}\left(\frac{(1-\alpha) \frac{a}{b} \kappa_{t}^{\alpha}}{(1-\alpha) \frac{a}{b} \kappa_{t}^{\alpha}+1}\right)^{\frac{\rho}{1-\rho}}\right)^{\frac{1-\rho}{\rho}} & \text { if } \quad k_{t} \geq k_{o} .
\end{array}\right.
$$

These expressions show that in both regimes, $k_{t+1}$ is increasing in $\kappa_{t}$ and thus, since $\kappa_{t}$ is an increasing function in $k_{t}$, the schedule $k_{t+1}\left(k_{t}\right)$ of the dynamic system is described by an increasing function.

We can now make two observations, which jointly imply the existence of a steady state under the second regime. First, the variable $\kappa_{t}$ determined by (22) or (23) as well as the threshold capital stock (24), is independent of $z$. Thus, given that $z$ is sufficiently large, an economy with per-household capital stock $k_{t}=k_{o}$ from (24) experiences positive capital growth due to capital accumulation (27): its capital stock in period $t+1$ exceeds its capital stock of the previous period, i.e. $k_{t+1}>k_{t}$ holds. Second, as $k_{t}$ grows unbounded, the ratio $\kappa_{t} / k_{t}=1 / m_{t}$ is bounded from above ${ }^{13}$. Thus, dividing the second line on the right hand side of equation (27) by $k_{t}$ shows that $k_{t+1} / k_{t}$ approaches zero as $k_{t}$ grows unbounded. Together, these findings imply that, if $z$ is sufficiently large, the dynamic system has a steady state in the second regime.

Our knowledge about the dynamics and the steady state of the system is sufficient to tell a simple story about economic development and female labor force participation. In an economy where capital is scarce, female labor force participation is zero. As time passes and per-household capital stock gradually accumulates, the rewards of formal employment for female workers increase relative to rewards for male workers. This closing of the gender wage

\footnotetext{
${ }^{13}$ See Appendix.
} 
gap fosters female labor force participation and curbs fertility. Both effects accelerate perhousehold capital accumulation, which continues under the second regime up to the point where the economy reaches its steady state.

\subsection{International Trade}

International trade in goods induces specialization at the country level so that countries expand some sectors while contracting others. If, as in the current model, sectors differ in factor intensity, international specialization affects relative factor prices within each country. In the following paragraphs, we explore these effects of trade, particularly its impact on the gender wage gap and hence on fertility and female labor force participation.

We assume that the world consists of two countries, Home $\left(\right.$ no $\left.^{*}\right)$ and Foreign $\left(^{*}\right)$. In addition, the superscript ${ }^{A}$ indicates autarky variables, while its absence indicates variables of the free trade equilibrium. Moreover, we denote the relative price of the two goods by $\pi_{t}=p_{2, t} / p_{1, t}$, the ratio of male to female wage by $\omega_{t}=w_{t}^{M} / w_{t}^{F}$, and the relative population size of Foreign to Home by $\lambda_{t}=L_{t}^{*} / L_{t}$. Without loss of generality Home will represent the capital scarce and Foreign the capital abundant country, i.e., we assume that $k_{t}<k_{t}^{*}$ for the initial period $t$. For later use, we define the set of all possible factor distributions in a world as:

$$
F D_{t}=\left\{\left(\lambda_{t}, k_{t}, k_{t}^{*}\right) \mid \lambda_{t} \in[0, \infty] ; k_{t}, k_{t}^{*} \geq 0 \text { and }\left(k_{t}+\lambda_{t} k_{t}^{*}\right) /\left(1+\lambda_{t}\right)=\bar{k}_{t}\right\}
$$

where $\bar{k}_{t}$ is the average per household capital stock of the world economy.

\subsubsection{Factor Price Equalization}

A good starting point for analysis of the free trade equilibrium is the Factor Price Equalization Set

$$
\operatorname{FPES}_{t}=\left\{\left(\lambda_{t}, k_{t}, k_{t}^{*}\right) \in F D_{t} \mid w^{M}=w^{*, M}, w^{F}=w^{*, F}, r^{F}=r^{*}\right\} .
$$


(Remember that the absence of superscript ${ }^{A}$ indicates equilibrium variables under free trade - e.g. at $w^{M}, w^{*, M}$ etc.) Among all possible distributions of factors across countries, the $F P E S_{t}$ comprises those that lead to free trade equilibria characterized by identical factor prices across countries. In terms of prices and output, these equilibria then replicate the equilibrium of an integrated world economy where factors are not restricted by national

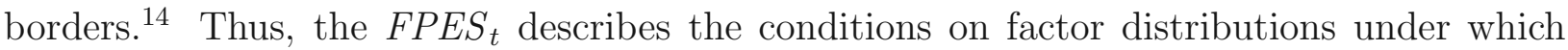
borders do not affect the world efficiency frontier. Loosely conceptualized, a factor allocation is an element of the $F P E S_{t}$ if relative factors are distributed "not too unevenly".

The following proposition conveniently characterizes the FPES $S_{t}$ of the present model.

\section{Proposition 1}

Under costless trade, the following statement holds: Factor prices equalize $\Leftrightarrow \kappa_{t}^{*}=\kappa_{t}$.

Proof. See Appendix.

The proposition shows that $\kappa_{t}=\kappa_{t}^{*}$ implies $\omega_{t}=\omega_{t}^{*}$, a regime in which fertility, determined by (15), equalizes in both countries: $z n_{t}=z n_{t}^{*}=z \bar{n}_{t} \cdot{ }^{15}$ Combined with $\kappa_{t}=\kappa_{t}^{*}=\bar{\kappa}_{t}$ this leads to:

$$
\bar{\kappa}_{t}=\frac{k_{t}}{l_{1, t}+1-z \bar{n}_{t}}=\frac{k_{t}^{*}}{l_{1, t}^{*}+1-z \bar{n}_{t}} .
$$

By the definition of the $F P E S_{t}, \bar{\kappa}_{t}$ and $\bar{n}_{t}$ are also the capital-mental labor ratio and fertility of the integrated world economy. The constraints $l_{1, t}, l_{2, t}^{*} \in[0,1]$ lead to a restriction on capital stock conditions for factor price equalization:

$$
\left(1-z \bar{n}_{t}\right) \bar{\kappa}_{t} \leq k_{t}, k_{t}^{*} \leq\left(2-z \bar{n}_{t}\right) \bar{\kappa}_{t}
$$

by the resource constraint. Capital stocks of both countries must add up to the aggregate world capital stock, i.e., $\bar{k}_{t}=\left(k_{t}+\lambda_{t} k_{t}^{*}\right) /\left(1+\lambda_{t}\right)$. Thus, the FPES is described by (31)

\footnotetext{
${ }^{14}$ If the equilibrium of the integrated economy is replicated, factors in all countries must equalize. Conversely, if factor and good prices equalize in both countries, the world equilibrium is an equilibrium of the integrated economy.

${ }^{15}$ Upper bars indicate variables of the integrated economy.
} 
and

$$
k_{t}=\left(1+\lambda_{t}\right) \bar{k}_{t}-\lambda_{t} k_{t}^{*}
$$

Using the concise graphical representation from Helpman and Krugman (1985), Figure 2 illustrates the $F P E S_{t}$. Each point $A$ on the plane represents a partition of world labor and world capital: the distance between the vertical axis and $A$ represents Home's male labor $L_{t}$, while the distance between the horizontal axis and $A$ represents Home's capital $K_{t}$; Foreign's variables are $L_{t}^{*}=\bar{L}_{t}-L_{t}$ and $K_{t}^{*}=\bar{K}_{t}-K_{t}$, respectively. The upper panel of Figure 2 shows the case $z \bar{n}_{t}<1$, where a minimum amount of capital is required in each country to keep female labor force productive in the first sector. The lower panel shows the case $z \bar{n}_{t}=1$. In this case, a country may entirely lack capital while the world economy is still at its efficiency frontier, replicating the equilibrium of the integrated economy.

We can now readily determine the specialization pattern of both economies under the assumption that factor prices equalize. Recalling assumption $k_{t}<k_{t}^{*}$, we observe:

$$
m_{t}=k_{t} / \bar{\kappa}_{t}<k_{t}^{*} / \bar{\kappa}_{t}=m_{t}^{*}
$$

while

$$
l_{2, t}=1-\left[m_{t}-\left(1-z \bar{n}_{t}\right)\right]>1-\left[m_{t}^{*}-\left(1-z \bar{n}_{t}\right)\right]=l_{2, t}^{*} .
$$

Confirming Heckscher-Ohlin-based intuition, the capital scarce Home country specializes in production of the labor intensive good, $X_{2}$, while capital abundant Foreign specializes in $X_{1}$-production.

We can further compare the trade equilibrium with the respective autarky equilibria: notice that $1-z \bar{n}_{t} \leq m_{t}<m_{t}^{*}$ implies $l_{1, t}^{*}>0$ so that $\omega_{t}^{*}=1+b /(a(1-\alpha)) \bar{\kappa}_{t}^{-\alpha}$ and (18) applies for Foreign. As $\omega_{t}^{*}=\omega_{t}$ and since $\kappa_{t}\left(k_{t}\right)$ is an increasing function, we use (18) again to conclude:

$$
z n_{t}^{A} \geq z \bar{n}_{t} \geq z n_{t}^{*, A}
$$


These inequalities are strict if $1>z n_{t}^{A}$ holds. Consequently, relative to autarky, trade increases female labor force participation in the capital scarce country and decreases it in the capital abundant country.

Both observations combined imply that the country which, by international specialization, contracts the sector that is particularly suitable for female labor, experiences an increase in female labor force participation. Conversely, the country which expands the sector suitable for female labor, experiences a decrease in female labor force participation.

The reason for this seemingly paradoxical finding is the following. For each economy, the key determinant of female labor force participation is the wage gap $\omega_{t}^{(*)}$. In autarky and under factor price equalization, this wage gap is determined by the relative productivities in the $X_{1}$-sector via (18) and ultimately by the capital-mental labor ratio $\kappa_{t}^{(*)}$. When international specialization induces Home to contract its $X_{1}$-sector and expand its $X_{2}$-sector, male workers move from the first to the second sector, taking their mental labor with them. Thus, they increase the ratio $\kappa_{t}$ and hence female labor force participation $\left(1-z n_{t}\right)$. Conversely, when Foreign workers react to trade-induced international price shifts and move from the second to the first sector, they dilute the capital-mental labor share $\kappa_{t}^{*}$, which increases the wage gap and decreases female labor force participation. ${ }^{16}$

In sum, under factor price equalization, we get sharp results on the impact of trade on female labor force participation in the capital scarce and abundant countries, respectively. The key mechanism for the result described above, however, depends on the fact that the wage gap is a function of only the capital-mental labor ratio $\kappa_{t}^{(*)}$. It may occur to the reader that international trade can induce male workers of one country to entirely abandon the first sector, while, at the same time, factor prices and the wage gap in particular do not equalize in both countries. If this is the case, the one-to-one relationship between $\kappa_{t}$ and

\footnotetext{
${ }^{16}$ The effect of relative productivities on the gender wage gap, which is the core of our mechanism operates under substantial generalizations. If $F(K, M, L)$ represents a standard constant return to scale production function in the first sector, it is sufficient to assume that capital $K$ complements mental labor $M$ relatively more than physical labor $L$ (i.e. , $F_{K M} / F_{M}>F_{K L} / F_{L} \geq 0$, in line with Goldin (1990)) in order to generate the effect discussed. In particular, under these conditions, higher male employment in the first sector increases the gender wage gap.
} 
$z n_{t}$ described by (18) does not hold and the mechanism described above ceases to apply. Consequently, our results under factor price equalization cannot be expected to hold under each and every factor distribution $\left(\lambda_{t}, k_{t}, k_{t}^{*}\right) \in F D_{t}$. The extent to which they generalize beyond factor price equalization is the subject of the next subsection.

\subsubsection{Beyond Factor Price Equalization}

Let us begin the general case of international trade by focusing on one country, for example, Home, with exogenous relative world prices $\pi_{t}$ - i.e., assume, for the moment, Home to be a small open economy. For this exercise, we abandon Home's role as the capital scarce country. When world prices coincide with Home's autarky price $\pi_{t}^{A}$, we have $l_{1, t}, l_{2, t}>0$, as argued in the case of the closed economy. Thus, by wages (10), (11), and (12) we find that:

$$
\begin{aligned}
\omega_{t} & =\pi_{t} \frac{b / a}{1-\alpha} \kappa_{t}^{-\alpha} \\
\pi_{t} & =(1-\alpha) \frac{a}{b} \kappa_{t}^{\alpha}+1
\end{aligned}
$$

hold for $\pi_{t}$ in a small neighborhood of $\pi_{t}^{A}$. Combine (33) and (34) to verify that in this neighborhood, the wage gap

$$
\omega_{t}=\frac{\pi_{t}}{\pi_{t}-1}
$$

is decreasing in $\pi_{t}$ and $z n_{t}$ is also decreasing by (15). Since $\kappa_{t}$ is increasing in $\pi_{t}$ by (34), $m_{t}=l_{1, t}+1-z n_{t}$ must be decreasing in $\pi_{t}$, which finally means that $l_{1, t}$ is decreasing in $\pi_{t}$. These relations hold as long as $l_{1, t}, l_{2, t}>0$ apply. Thus, by the constraints $l_{1, t} \in[0,1]$, there are thresholds $\underline{\pi}$ and $\bar{\pi}$ with $\underline{\pi}<\pi_{t}^{A}<\bar{\pi}$ so that for $\pi_{t}<\underline{\pi}$, we have $l_{1, t}=1$ and $\kappa_{t}$ as well as the wage gap $\omega_{t}$ defined by (17) are constant. Conversely, for $\pi_{t}>\bar{\pi}$, we have $l_{1, t}=0$ in which case (33) holds and $\kappa_{t}=k_{t} /\left(1-z n_{t}\right)$ and (15) imply:

$$
\frac{\omega_{t}}{\left(1-\gamma\left(1+\omega_{t}\right)\right)^{\alpha}}=\pi_{t} \frac{b / a}{1-\alpha} k_{t}^{-\alpha}
$$


This equation defines $\omega_{t}$ as an increasing function of $\pi_{t}$. Finally, at $\pi_{t} \rightarrow \infty$ equation (36) implies $\omega_{t} \rightarrow(1-\gamma) / \gamma$.

Figure 3 summarizes these findings of the function $\omega_{t}\left(\pi_{t}\right)$. For small $\pi_{t}$, the wage gap $\omega_{t}$ is constant. For the intermediate range $\pi_{t} \in(\underline{\pi}, \bar{\pi})$, the wage gap $\omega_{t}\left(\pi_{t}\right)$ is decreasing but for $\pi_{t}>\bar{\pi}$ it is increasing. By the generic relation (15), these swings in $\omega_{t}$ are paralleled by swings in $z n_{t}$.

Now consider the Home economy facing relative world prices $\pi_{t}<\pi_{t}^{A}$. This means that, relative to autarky, the wage gap $\omega_{t}$ increases and, hence, fertility $n_{t}$ rises while female labor participation $\left(1-z n_{t}\right)$ drops. At the same time trade expands the $X_{1}$-sector and contracts the $X_{2}$-sector. ${ }^{17}$ If, instead, $\pi_{t}>\pi_{t}^{A}$, there are two possible outcomes. First, if $\pi_{t}$ is not too large, then the effect of trade is a reduction in the wage gap $\omega_{t}$ and thus a decrease in fertility $n_{t}$ and an increase in female labor force participation $\left(1-z n_{t}\right)$. Second, if $\pi_{t}$ is sufficiently large, then trade induces an increase in $\omega_{t}$ and $n_{t}$ and a decrease in $\left(1-z n_{t}\right)$. In Figure 3 , the threshold that separates the two cases is labeled $\pi_{u}$. In either case, trade contracts the $X_{1}$-sector and expands the $X_{2}$-sector. ${ }^{18}$

Now, return to the trade equilibrium between capital scarce Home and capital abundant Foreign. The autarky prices of both countries satisfy (34), implying $\pi_{t}^{A}<\pi_{t}^{*, A}$, while the world price under free trade $\pi_{t}$ must lie between the respective autarky prices:

$$
\pi_{t}^{A} \leq \pi_{t} \leq \pi_{t}^{*, A}
$$

Thus, trade (weakly) increases relative prices $\pi_{t}$ in Home while it (weakly) decreases them in Foreign. With this observation, we can apply the insights of the analysis above. For capital

\footnotetext{
${ }^{17}$ To see this, notice that $\pi_{t}<\pi_{t}^{A}$ implies $l_{1, t}>l_{1, t}^{A}$ and, as $(34)$ holds, $\kappa_{t}<\kappa_{t}^{A}$. This, in turn leads to $m_{t}>m_{t}^{A}$ so that total output in the first sector $a k_{t}^{\alpha} m_{t}^{1-\alpha}+b l_{1, t}$ rises relative to autarky. Output of the second sector $b\left(1-l_{1, t}\right)$ drops.

${ }^{18}$ Observe that $\pi_{t}>\pi_{t}^{A}$ implies $l_{1, t}<l_{1, t}^{A}$ so output in the second sector $b\left(1-l_{1, t}\right)$ expands in both cases. Further, for $\pi_{t}<\bar{\pi}$ (34) holds, implying $\kappa_{t}>\kappa_{t}^{A}$ or $m_{t}<m_{t}^{A}$. Any increase in $\pi_{t}$ above $\bar{\pi}$ reduces female labor $1-z n_{t}$ while $l_{1, t}=0$ continues to hold. Thus, $m_{t}<m_{t}^{A}$ in this range, too. Together, this means that output in the first sector $a k_{t}^{\alpha} m_{t}^{1-\alpha}+b l_{1, t}$ falls.
} 
abundant Foreign, trade unambiguously causes a (weak) increase in the wage gap $\omega_{t}$ and thus a drop in female labor force participation. We can therefore generalize the first part of our result derived under factor price equalization. The country which, by international specialization, expands the sector suitable for female employment experiences a decrease in female labor force participation.

For capital scarce Home, however, trade induces a decrease in the wage gap $\omega_{t}$ and an increase in female labor force participation if and only if $\pi_{t}$ is not too high (i.e., $\pi_{t} \leq \pi_{u}$ holds). In this restricted case, we recover the second part of the result derived under factor price equalization. The country which contracts the sector suitable for female labor experiences an increase in female labor force participation.

This second observation is a non-trivial generalization of the parallel result under factor price equalization. To verify this statement, use that under free trade $l_{1, t}^{*}>0$ and $l_{2, t}>0$ hold so that, by (10) and (11)

$$
(1-\alpha) \frac{a}{b}\left(\kappa_{t}^{*}\right)^{\alpha}+1 \geq \pi_{t} \geq(1-\alpha) \frac{a}{b} \kappa_{t}^{\alpha}+1
$$

holds. Proposition 1, however, states that factor price equalization requires $\kappa_{t}=\kappa_{t}^{*}$, implying $\pi_{t}=(1-\alpha) \frac{a}{b} \kappa_{t}^{\alpha}+1$. By construction of $\bar{\pi}$, however, all world equilibria with $\pi_{t} \in\left(\bar{\pi}, \pi_{u}\right)$ are characterized by equality $\pi_{t}>(1-\alpha) \frac{a}{b} \kappa_{t}^{\alpha}+1$, implying that factor prices do not equalize. Since finally, by construction of $\pi_{u}$ we have $\omega_{t}>\omega_{t}^{A}$ for all equilibria with $\pi_{t} \in\left(\bar{\pi}, \pi_{u}\right)$ we conclude that trade induces an increase of female labor force participation in Home for a set of factor endowments that is strictly larger than the FPES .

Summarizing, we use the definitions (28) and (29) to state the following proposition.

\section{Proposition 2}

(i) In Foreign, trade expands the sector that uses female labor intensively, but unambiguously reduces female labor force participation.

(ii) There is a set $S_{t} \subset F D_{t}$ with FPES $\varsubsetneqq S_{t}$ and the following property: for each element 
of $S_{t}$ trade contracts the sector that uses female labor intensively in Home, but increases Home's female labor force participation.

\subsubsection{Dynamics under Trade}

The dynamics of the model under free trade are again driven by two key variables, savings $s_{t}$ and fertility $n_{t}$. Per-household capital stocks of either country follow the generic dynamic system equivalent to (25), now expanded to:

$$
k_{t+1}^{(*)}= \begin{cases}z w_{t}^{M,(*)} & \text { if } z n_{t}^{(*)}=1 \\ z \frac{1-\gamma}{\gamma} w_{t}^{F,(*)} & \text { if } z n_{t}^{(*)}<1\end{cases}
$$

To calculate the respective wages (10) - (12), we can use the final good normalization (8) and the definition of $\pi_{t}$ to derive:

$$
p_{1, t}=\left(\theta^{\frac{1}{1-\rho}}+(1-\theta)^{\frac{1}{1-\rho}} \pi_{t}^{\frac{-\rho}{1-\rho}}\right)^{(1-\rho) / \rho} \quad \text { and } \quad p_{2, t}=\left(\theta^{\frac{1}{1-\rho}} \pi_{t}^{\frac{\rho}{1-\rho}}+(1-\theta)^{\frac{1}{1-\rho}}\right)^{(1-\rho) / \rho}
$$

These defined wages and dynamic system, (39), give rise to the following observations

\section{Proposition 3}

(i) $z n_{t}^{*} \leq z n_{t}$.

(ii) $k_{t+1}^{*} \geq k_{t+1}$.

(iii) If $\alpha(\theta /(1-\theta))^{\frac{-1}{1-\rho}} \geq(1-2 \gamma) / \gamma$ holds then $k_{t+1} \geq k_{t+1}^{A}$.

(iv) $k_{t+1}^{*} / k_{t+1} \leq k_{t+1}^{*, A} / k_{t+1}^{A}$.

Proof. See Appendix.

Proposition 3 (i) and (ii) show that trade cannot reverse the order of countries regarding population growth or capital abundance. The capital rich country has always weakly lower fertility rates, higher female labor force participation and faster pace of per-household capital accumulation. 
Proposition 3 (iii) shows that, given that the first sector is sufficiently large (i.e., $1-\theta$ is sufficiently small), trade unambiguously accelerates the pace of capital accumulation in the capital scarce country. It is worth emphasizing that this result also holds in the case where world prices $\pi_{t}$ are very large and all men in Home work in the $X_{2}$-sector while female labor participation drops relative to autarky $\left(\pi_{t}>\pi_{u}\right.$ in Figure 3). Even in this case, where a reduced female labor force participation depresses savings and increased population growth dilutes the following period's per household capital stock, the gains from trade are sufficient to grant a net increase in per-household capital accumulation relative to autarky. We cannot, however, make a parallel statement for the capital rich economy, for which the effect of trade on capital accumulation is ambiguous. Indeed, it can be shown that for capital accumulation in the rich economy, the positive forces stemming from the gains of trade might either dominate or be dominated by the adverse effect of reduced female labor force participation and higher fertility.

Finally, Proposition 3 (iv) makes a relative statement about the countries' capital accumulation. Trade cannot accelerate capital accumulation in the rich country by more than it accelerates it in the poor country. In particular, the proposition shows that trade spurs convergence of per-household capital stocks. At the same time, using Proposition 3 (ii) and (iv), a simple induction argument leads to $k_{t+\tau}^{*} / k_{t+\tau} \leq k_{t+\tau}^{*, A} / k_{t+\tau}^{A}$ for all $\tau \geq 0$ and hence:

$$
\lim _{t \rightarrow \infty} k_{t}=\lim _{t \rightarrow \infty} k_{t}^{*}=\tilde{k}
$$

Since in the limit, factor endowments between countries equalize, the motives to trade disappear. Consequently, the limit $\tilde{k}$ is equal to the limit of the closed economy: $\tilde{k}=k$, where $k$ is the steady state capital stock of the closed economy.

Summarizing Proposition 3, international trade fosters convergence in fertility, labor force participation, and per-household capital stocks. 


\subsection{Technological Progress}

The reduction in the gender wage gap is often attributed to technological change. Thus, Welch (2000), Gosling (2003) and Black and Spitz-Oener (2007) argue that the increase in the market price for women's labor was brought about by a relative increase in the valuation of skill (mental labor endowments), which is, at least in part, explained by technological change. Galor and Weil (1996) show how technological change can eliminate poverty traps, characterized by high fertility, low female labor force participation and low per-household capital stocks. They argue that "technological progress will eventually eliminate such a development trap, leading to a period of rapid output growth and a rapid fertility transition" (p. 383).

Another popular hypothesis rests on demand shifts in favor of goods whose production is more intensive in skill or, more generally, in female labor inputs. The mechanism outlined above, in which, male workers searching for the highest return to their labor crowd out women in the labor market sheds some doubt on the generality of these pro-growth effects. Indeed, we show next that the effect that leads to a decrease in female labor force participation and an increase in fertility in response to the expansion of the females' comparative advantage sector operates under technological change and shifts in demand as well.

For the formal analysis of technological change and demand shifts, we return to the closed economy. To incorporate technological change biased towards the sectors that generate demand for female labor, we rewrite the production functions (2) as:

$$
\begin{aligned}
& X_{1}=\mu\left[a K_{t}^{\alpha}\left(L_{t}^{m}\right)^{1-\alpha}+b L_{1, t}^{p}\right] \\
& X_{2}=b L_{2, t}^{p}
\end{aligned}
$$

so that growth of the parameter $\mu \geq 1$ mimics technological progress that is biased towards 
the first sector. As a result of incorporating $\mu$ into our framework (23) becomes ${ }^{19}$

$$
\frac{\theta}{1-\theta} \mu^{\rho}\left[(1-\alpha) \frac{a}{b} \kappa_{t}^{\alpha}+1\right]=\left(\frac{\frac{a}{b} \frac{k_{t}}{\kappa_{t}^{1-\alpha}}+\frac{k_{t}}{\kappa_{t}}-1+\gamma\left(2+\frac{b}{a} \frac{\kappa_{t}^{-\alpha}}{1-\alpha}\right)}{1-\frac{k_{t}}{\kappa_{t}}+1-\gamma\left(2+\frac{b}{a} \frac{\kappa_{t}^{-\alpha}}{1-\alpha}\right)}\right)^{1-\rho}
$$

While the right hand side of (42) is decreasing in $\kappa_{t}$, the left hand side of (42) is increasing in $\kappa_{t}$ and in $\mu$, for $\rho \in(0,1)$. This implies that an increase in $\mu$ decreases the equilibrium level of $\kappa_{t}$, which, in turn, decreases female's productivity relative to male productivity, widens the gender wage gap and curbs female labor force participation.

After reading the previous subsections, the intuition for this result is straightforward. An increase in $\mu$ increases male productivity in the first sector relative to the second sector. As long as the elasticity of substitution between $X_{1}$ and $X_{2}$ is greater than one, the relative price $\pi$ decreases but the decrease is less than the increase in $\mu$. As a result, male wage increases in the first sector, inducing male workers to move from the second sector to the first sector. This increases mental labor employed in the first sector and dilutes $\kappa$ so that women's relative productivity declines, driving women out of formal employment into the child-rearing.

A similar mechanism applies under demand shifts towards the first good, equivalent to an increase in the parameter $\theta$ (compare (1)). Again, equation (42) shows that an increase in $\theta$ is followed by a decrease in $\kappa_{t}$, which curbs women's productivity by more than men's, widens the wage gap and thus decreases female labor force participation while fostering fertility.

Thus, our model shows that neither a technological change biased towards sectors with a high demand for female labor nor demand shift towards goods of these sectors necessarily generates increases in female labor participation. The resulting increase in fertility generally counters the pro-growth effects.

\footnotetext{
${ }^{19}$ Under $\mu \geq 1$ condition (16) is sufficient for $l_{1, t}^{p}>0$ to hold, i.e., male employment in the first sector is positive.
} 


\section{$3 \quad$ Empirical Evidence}

Our theory predicts an asymmetric impact of trade liberalization on the labor markets of capital rich and capital scarce economies: while trade lowers female labor force participation in the former, it tends to increase it in the latter. We like to think of our theory in the context of long run growth and frame it with a model of demographic transition. In light of data limitations, however, we choose to test the predictions through the surge in U.S.-Mexican trade during the period 1990-2007, a period of trade liberalization, which we simply label the "NAFTA episode" in the following ${ }^{20}$.

The choice of the NAFTA episode has a number of virtues. First, the U.S. and Mexico are paradigmatic for a pair of capital rich and capital poor economies, for which our theory applies. $^{21}$ As a second advantage of the NAFTA episode, U.S.-Mexican trade experienced a substantial growth during that period: U.S. trade with Mexico as a share of U.S. GDP increased by more than a factor of 3 between 1990 and 2007, while Mexico's share in U.S. total trade rose by more than a factor of 2 (Figure 4). Via this substantial increase of bilateral trade volumes we hope to identify a sizable impact of trade on labor markets. Third, the choice of the NAFTA episode allows us to take advantage of the high quality of U.S. trade and labor market data. In particular, we can exploit exposure to trade with Mexico on a U.S. state level. Finally, due to the specific geographical constellation, U.S. trade with Mexico is particularly uneven across U.S. states, which allows us to use distance as a powerful instrument for a change in trade volumes and thus establish causality running from change in trade to change in female labor share.

\footnotetext{
${ }^{20}$ This label is misleading to the extent that not all of the increase in US-Mexican trade is attributed to tariff reductions of NAFTA. In fact, Krueger (1999) puts forward that Mexico's unilateral tariff reduction in the late 1980s and its abandoning of the exchange rate peg explains the larger part of the increase in trade volumes. For the purpose of our test, however, this observation is of minor importance. We are only concerned about identifying an episode of substantial increase in trade volumes.

${ }^{21}$ Capital stocks per worker can be calculated from real investment data as in PWT6.2. At depreciation rates between .01 and .1, the relative capital stock of the U.S. in 2003 exceeds the one of Mexico by a factor of four. Consistent with our theory, the female labor share in the U.S. ranged from 43.1 to 46.3 between 1985 and 2006 while the according range for Mexico is 29.4 to 35.3 (United Nations Statistics Division).
} 


\subsection{Data}

We rely on three different data sources. First, we use data from the March Current Population Survey conducted by the Integrated Public Use Microdata Series (IPUMS-CPS). ${ }^{22}$ From (IPUMS-CPS) we take the variables age, sex, marital status, population status (to distinguish between civilian or Armed Forces), nativity (to identify immigrants), location (state), Hispanic origin (to identify Mexicans), educational attainment, employment status (to compute the formal employment share) weeks worked and usual hours worked (to compute total hours worked). Table 1 provides descriptive statistics for female and male labor for the years 1990/91 and 2006/07. As is visible in Table 1, while female labor force participation has increased, male labor force participation has decreased during the NAFTA episode. Second, we use the "Origin of Movement" database administered by WISER, ${ }^{23}$ which covers export data by state and destination country from 1988 onward. These data are disaggregated by good categories (SIT2 from 1988 to 2000; NAICS from 1997 onward). Third, we use the Bureau of Economic Analysis for GDP by state data. ${ }^{24}$

\subsection{The Empirical Model}

In our empirical exercise we concentrate on one side of our theory and aim at identifying the effect of trade on the U.S. labor market (the capital rich economy). More precisely, we exploit the variation of U.S.-Mexican trade across different U.S. states to identify the differential impact of trade on female labor share across states. ${ }^{25}$ According to our theory, a higher exposure to trade with Mexico induces lower female labor force participation in

\footnotetext{
${ }^{22}$ King, Ruggles, Alexander, Leicach and Sobek (2009).

${ }^{23}$ World Institute for Strategic Economic Research; data available under http://www.wisertrade.org. Cassey (2006) gives a good introduction to the data and their limitations.

${ }^{24}$ data available under http: http://bea.doc.gov/regional/.

${ }^{25}$ The focus on U.S. states as economic entities may seem problematic since state borders are not relevant restrictions for the labor. This drawback, however, implies that inter-state labor migration can eliminate differences in the wage gap and female labor force participation across states, which tends to eliminate the differential effects of trade across states. Thus, no differential effect of trade on female labor shares across states can be expected as long as the U.S. labor market works frictionless. We nevertheless expect to capture labor markets effects to the extent that frictions of labor movement related to geographical distance impede a full equalization of factor prices across U.S. states.
} 
the different U.S. states. Analyzing this relation on the state level, our reduced form model takes the following form

$$
y_{s t}=\delta_{s}+\alpha t+\beta \operatorname{Trade}_{s t}+X_{s t}^{\prime} \gamma+u_{s t}
$$

where $s$ indicates U.S. states and $t$ periods. The dependent variable $y_{s t}$ is the female labor share, Trade $_{s t}$ is trade volume per output and $\delta_{s}$ denotes a full set of state dummies. Apart form a time-trend we control for a vector of covariates $X_{s t}^{\prime}$ chosen by economic intuition but unrelated to our theoretical model. Our initial period is $1990-1$, denoted by $t=0$, while the end period is 2006-7, denoted by $t=1 .^{26}$

Taking differences eliminates the state fixed effects and the empirical model (43) becomes

$$
\Delta y_{s}=\alpha+\beta \Delta \text { Trade }_{s}+\Delta X_{s}^{\prime} \gamma+u_{s 1}-u_{s 0}
$$

where for any variable $z_{s t}$ the notation $\Delta z_{s}$ indicates the change over time $\left(\Delta z_{s}=z_{s 1}-z_{s 0}\right)$. Our theory predicts that the estimate of $\beta$ in (44) is negative.

Concerned with the possibility that labor market conditions in the U.S. can constitute a form of comparative advantage and thus drive trade volumes, we slightly modify the gravity equation of the trade literature and instrument Trade $_{s t}$ by distance to Mexico. ${ }^{27}$ Thus, our first stage regression is:

$$
\operatorname{Trade}_{s t}=\varrho_{s}+\mu t+\theta d_{s} t+X_{s t}^{\prime} \rho+\nu_{s t}
$$

where $\varrho_{s}$ denotes a full set of state dummies and $d_{s}$ is distance of state $s$ to Mexico. By

\footnotetext{
${ }^{26}$ This time window is determined by availability of trade data. The data set includes entries for the years $1988 / 89$ but these are of minor quality.

${ }^{27}$ More precisely, we regress trade volume as a percentage of GSP on spherical distance of U.S. statecapitals to Mexico City, while the standard gravity equation estimates the log of bilateral trade volume on the log of GDP, spherical distance and other variables. Our justification is the fit of the data. For a more elaborate and elegant way for instrumenting trade with distance see Feyrer (2009).
} 
taking differences our first stage regression becomes:

$$
\Delta \operatorname{Trade}_{s}=\mu+\theta d_{s}+\Delta X_{s}^{\prime} \rho+\nu_{s 1}-\nu_{s 0}
$$

Figure 5 illustrates that distance is strongly correlated with the increase in trade share, satisfying a first necessary condition for being a valid instrument. ${ }^{28}$

\subsection{Control Variables}

To control for differential business cycle effects across states we include log per capita "Gross State Product" (GSP) and the unemployment rate. We also control for average education level for females, which is positively correlated with female labor share. ${ }^{29}$ Further, we include the share of Mexican immigrants, which might either depress female labor participation - e.g. due to cultural differences reducing gender labor market participations ${ }^{30}$ - or else increase female labor participation - e.g. by increasing supply of nannies and private child-care. We have no strong prior on the sign of this latter control variable.

The secular trend towards higher female labor force participation together with the fact that it is naturally bounded from above implies that female labor force participation con-

\footnotetext{
${ }^{28}$ By our identifying assumption, distance to Mexico does not impact the change in female labor shares across U.S. states through other channels than bilateral trade. To lend support to this assumption we examine the quality of distance as an instrument by comparing its explanatory power for the change in female labor force participation in two different periods: first, 1990-2000, in which we observe a substantial increase in U.S.-Mexican trade; and second, 1960-1970, in which U.S.-Mexican trade was stagnant, which we simply label the "pre-NAFTA episode" (Figure 4). To this end, we employ the 1 percent Integrated Public Use Microdata Series (IPUMS-USA) of the decennial censuses data (Ruggles, Sobek, Alexander, Fitch, Goeken, Kelly Hall, King and Ronnander (2009)). This source provides us with employment data for men and women for the years 1950, 1960 and 1970 for the pre-NAFTA period, and 1980, 1990 and 2000 for the NAFTA period. Table A-1 (see Appendix) summarizes these reduced form regressions of female labor force participation directly on distance in the two episodes and shows that during the NAFTA period the coefficient of distance is positive and significant while in the pre-NAFTA period is negative and sometimes insignificant, which is consistent with our story.

${ }^{29}$ We define two categories of education. First, educated individuals who have at least some college and for whom we assign a weight of 1 . Second, uneducated individuals who are at most high school graduates and for whom we assign a weight of 0 . The education level of a state is defined as the average of individual weights.

${ }^{30}$ On a national level, this concern seems unsubstantiated: national averages of female hours worked as percentage of male hours worked of Mexicans exceed the according numbers of the full sample by $0.5 \%$ to $1.9 \%$ between 1990 and 2007.
} 
verges across states. Hence, the initial levels of female labor share is highly correlated with its changes. To account for this convergence effect, we include initial level of female labor force participation in the controls when estimating (44). A problem with this control variable, however, is that it is correlated with the error term $u_{i 1}-u_{i 2}$ in (44) through equation (43), wherefore we instrument it with lagged female labor participation (values from 1980/81).

\subsection{Regression Results}

For our baseline specification we define female labor participation as the share of hours worked by females. Taking this share is not a strict necessity but it eliminates labor market shocks that are common to both sexes. In all our specifications labor force is defined as the total of individuals aged between 16 and 65, excluding members of the Armed Forces. We further define exposure to trade as twice the state exports to Mexico over GSP. The restriction to exports is due to the fact that import data per state are not available. ${ }^{31}$ Distance is spherical distance from state-capitals to Mexico City.

Table 2 reports the results of our baseline regression. Column 1 reports a simple OLS regression of our dependent variable: change in female labor share on an initial level of female labor share, which we take it to be the average of 1980 and 1981 and the change in trade with Mexico. Our focus, however, lies on the remaining five columns that summarize IV estimates, where the change in trade is instrumented by distance. Column 2 reports estimates without controls, column 3 includes average female labor share of 1990 and 1991, which is instrumented by the average values of 1980 and 1981; column 4 includes the differences of log per capita GSP and unemployment share; column 5 includes differences in female education share and column 6 includes change in Mexican immigration share.

The coefficient of our interest is the one on change in trade with Mexico $(\beta)$. All of its estimates have the expected negative sign and are significant on the one percent confidence level. Column 3, indicates that a one percent increase in trade share with Mexico (as

\footnotetext{
${ }^{31}$ We assume that import equalizes export in order to reveal, quantitatively, a more realistic coefficient of trade on female labor share.
} 
experienced by Arizona) decreases the female relative to male labor share by around 1.5 percent. The coefficient on the initial level of female labor share is negative and significant, as predicted by convergence forces. ${ }^{32}$

\subsection{Robustness}

We next conduct some robustness check for the results obtained in the baseline regression (column 3 in Table 2). First, we exclude Texas as well as Alaska and Hawaii from the sample since these states appear to be outliers in terms of distance (see Figure 5), and hence in predicted trade shares. Table 3 summarizes the corresponding results in the first three columns. The exclusions do not affect the general picture: the impact of trade share with Mexico remains negative and significant at the $1 \%$ level ( $5 \%$ in column 3 ).

We are also concerned about our definition of trade shares, since Cassey (2006) reports that export data exhibit systematic differences between "origin of movement definition" and "origin of production." Since these errors are substantial in the agricultural and mining sectors only, we replace total export over GSP per state by the according manufacturing export percentages. Column 4 in Table 3 shows that our concerns are unsubstantiated: the estimates are still significant at the $1 \%$ level and estimated magnitudes are very similar.

In trade literature the standard measure for distance is the spherical one (spherical distance between capitals). We check whether our results depend on the choice of distance and replace it by ground distance to the Mexican border (column 5 in Table 3). ${ }^{33}$ Results show that neither the point estimates nor the significance level are affected.

Since our theory rests on the within household optimization, it seems appropriate to restrict our sample to married individuals only. Column 6 in Table 3 shows that the point estimates and the significance remain in the same range ( $5 \%$ level).

Next we replace the definition of our dependent variable from share of hours to relative

\footnotetext{
${ }^{32}$ Table 2 shows that the OLS estimate is larger than IV estimate. One possible interpretation from this difference, which is consistent with our theory is that higher female labor force participation induces a higher relative advantage in the capital intensive sector which implies higher international specialization and trade.

${ }^{33}$ Ground distance is measured in time and derived from maps.google.com.
} 
employment. This obviously eliminates the important intensive margin of individuals' labor market participation. Column 7 in Table 3 shows that the estimates are significant at the $5 \%$ level.

Our theory suggests that trade-induced specialization reduces female labor force participation in capital rich country while making male workers merely change sectors. Consequently, we need to check that our results above are driven by changes in female employment only. We do so by investigating the impact of trade on female and male working hours separately. Average female hours per week are 22.77 (standard deviation across states is 1.92) in 1990/1991 and 24.24 (1.84) in 2006/2007. The according numbers for male are 32.92 (1.89) and $32.2(1.81)$, respectively (Table 1). These regressions are summarized in Table A-2. ${ }^{34}$ While all point estimates of the coefficient on change in trade share with Mexico are negative and significant for females, trade, overall, does not significantly impact male hours: estimates are insignificant, positive and around zero.

\section{Concluding Remarks}

This paper analyzes how expansions and contractions of sectors that use female labor intensively affect aggregate female labor force participation. We argue that when international trade expands sectors conductive to female employment, female labor force participation drops and vice versa. This is because male workers earn higher wages than women and are therefore always formally employed. Thus, when an economy specializes in sectors intensively use female labor, other sectors contract and male workers move to the expanding sectors, driving female workers out of formal employment.

Interestingly, Our mechanism also applies in the case of technological progress, which is biased towards female labor. In particular, technological progress biased towards FRAS increases the wages in this sector. This increase in wages attracts male workers who leave the

\footnotetext{
${ }^{34}$ Column 2, 4, 6 and 8 in Table A-2 show that using population weight to unravel the impact of change in trade at the individual level does not change neither the magnitudes of our estimates nor their significance.
} 
MRAS, an effect that can be strong enough to drive female workers out of formal employment. In this way, technological progress biased towards female labor might curb female labor force participation.

Turning to the dynamics, our model suggests that international trade fosters per-household capital growth in the capital scarce economy. In the capital abundant economy, however, the impact of international trade on capital growth is ambiguous. Although international trade hinders female labor force participation and increases fertility, domination of these adverse effects by positive forces stemming from gains from trade may occur. In both cases, our model suggests that trade cannot accelerate capital accumulation in the rich country by more than it accelerates capital accumulation in the poor country and, thus, our theory predicts convergence of per-household capital stocks.

Finally, we test our theory using bilateral trade data for the U.S. and Mexico. We exploit U.S. cross-state variation in the exposure to trade with Mexico to examine how trade has impacted female labor force participation. Instrumenting trade shares with geographic distance, our cross-state regressions support the hypothesis that, in rich economies, international trade with poor countries tends to reduce female labor supply. These findings are robust to various definitions of female labor supply and a set of controls.

\section{References}

Acemoglu, Daron, David H. Autor, and David Lyle, "Women, War, and Wages: The Effect of Female Labor Supply on the Wage Structure at Midcentury," Journal of Political Economy, 2004, $112(3), 497-551$.

Angrist, Joshua D. and William N. Evans, "Children and Their Parentsy Labor Supply: Evidence from Exogenous Variation in Family Size," The American Economic Review, June 1998, 88 (3), 450-477. 
Bagwell, Kyle and Robert W. Staiger, "Domestic Policies, National Sovereignty, and International Economic institutions," Quarterly Journal of Economics, May 2001, 116 (2), 519-562.

Bailey, Martha J., "More power to the pill: The impact of contraceptive freedom on women's lifecycle labor supply," Quarterly Journal of Economics, 2006, 121 (1), 289320.

Becker, Gary S., The Economics of Discrimination, Chicago: University of Chicago Press, 1957.

_ _ "An Economic Analysis of Fertility," in "Demographic and Economic Change in Developed Countries: a conference of the Universities-National Bureau Committee for Economic Research," Princeton, NJ: Princeton University Press, 1960, pp. 209-231.

Berik, Gunseli, Rodgers van der Meulen, and Joseph Zveglich, "International Trade and Gender Wage Discrimination: Evidence from East Asia," Review of Development Economics, 2004, 8, 23754.

Black, Sandra and Elizabeth Brainerd, "Importing Equality? The Impact of Globalization on Gender Discrimination," Industrial and Labor Relations Review, 2004, 57, $540-549$.

Black, Sandra E. and Alexandra Spitz-Oener, "Explaining Womens Success: Technological Change and the Skill Content of Womens Work," May 2007. IZA DP No. 2803.

Brown, Drusilla K., "Labor Standards: Where Do They Belong on the International Trade Agenda?," Journal of Economic Perspectives, 2001, 15 (3), 89-112.

Cassey, Andrew, "State Export Data: Origin of Movement vs. Origin of Production," 2006. Unpublished manuscript. 
Cunat, Alejandro and Marc J. Melitz, "Volatility, Labor Market Flexibility, and the Pattern of Comparative Advantage," 2007. NBER Working Paper 13062.

Davis, Donald R., "Does European Unemployment Prop up American Wages? National Labor Markets and Global Trade," The American Economic Review, Jun 1998, 88 (3), $478-494$.

Doepke, Matthias, Moshe Hazan, and Yishay D. Maoz, "The Baby Boom and World War II: A Macroeconomic Analysis," December 2007. NBER Working Paper 13707.

Feenstra, Robert C., Robert E. Lipsey, Haiyan Deng, Alyson C. Ma, and Henry Mo, "World Trade Flows: 1962-2000," January 2005. NBER Working Paper No. W11040.

Fernández, Raquel, "Culture as Learning: The Evolution of Female Labor Force Participation over a Century," August 2007. Unpublished manuscript, NYU.

Feyrer, James, "Distance, Trade, and Income - The 1967 to 1975 Closing of the Suez Canal as a Natural Experiment," 2009. Unpublished manuscript.

Galor, Oded, "From Stagnation to Growth: Unified Growth Theory," in Philip Aghion and Steven N. Durlauf, eds., Handbook of Economic Growth, Vol. 1A, Amsterdam: Elsevier, 2005, pp. 171-293.

and Andrew Mountford, "Trading Population for Productivity: Theory and Evidence," Review of Economic Studies, February 2008, 75 (1), 1143-1179.

and David N. Weil, "The Gender Gap, Fertility, and Growth," American Economic Review, June 1996, 86 (3), 374-387.

and __ "From Malthusian Stagnation to Modern Growth," American Economic Review, May 1999, 89 (2), 150-154. 
_ and _ _ , "Population, Technology, and Growth: From Malthusian Stagnation to the Demographic Transition and Beyond," American Economic Review, September 2000, $90(4), 806-828$.

and Omer Moav, "Natural Selection and the Origin of Economic Growth," Quarterly Journal of Economics, November 2002, 117 (4), 1113-1191.

Goldin, Claudia, Understanding the Gender Gap: An Economic History of American Women, NY: Oxford University Press, 1990.

_ _ "Career and Family: College Women Look to the Past," in F. Blau and R. Ehrenberg, eds., Gender and Family Issues in the Workplace, New York: Russell Sage Press, 1995, pp. $20-58$.

_ _ "The Quiet Revolution That Transformed Womens Employment, Education, and Family," American Economic Review, May 2006, 96 (2), 1-21.

Gosling, Amanda, "The Changing Distribution of Male and Female Wages, 1978-2000: Can the Simple Skills Story be Rejected?," September 2003. CEPR Discussion Paper No. 4045.

Greenwood, Jeremy and Ananth Seshadri, "Technological Progress and Economic Transformation," in Philippe Aghion and Steven N. Durlauf, eds., Handbook of Economic Growth, Vol. 1B, Amsterdam: Elsevier North-Holland, 2005, pp. 1225-1273.

Hazarika, Gautam and Rafael Otero, "Foreign Trade and the Gender Earnings Differential in Urban Mexico," Journal of Economic Integration, 2004, 19 (2), 353 - 373.

Helpman, Elhanan and Oleg Itskhoki, "Labor Market Rigidities, Trade and Unemployment," 2007. NBER Working Paper 13365.

and Paul Krugman, Market Structure and Foreign Trade, MIT Press Cambridge, MA; London, England, 1985. 
Heston, Alan, Robert Summers, and Bettina Aten, Penn World Table Version 6.2 Center for International Comparisons of Production, Income and Prices at the University of Pennsylvania September 2006.

King, Miriam, Steven Ruggles, Trent Alexander, Donna Leicach, and Matthew Sobek, Integrated Public Use Microdata Series, Current Population Survey: Version 2.0 [Machine-readable database]. Minneapolis, MN: Minnesota Population Center [producer and distributor], cps.ipums.org 2009.

Krueger, Anne O., "Trade Creation and Trade Diversion under NAFTA," 1999. NBER Working Paper No. 7429.

Maddison, Angus, The World Economy: A Millellennial Perspective, Paris: OECD, 2001.

Mincer, Jacob, "Market prices, Opportunity Costs, and Income Effects," in F. Christ Carl, ed., Measurement in Economics: Studies in mathematical economics and econometrics in memory of Yehuda Grunfeld, carl, f. christ ed., Stanford, CA: Stanford University Press, 1963, pp. 67-82.

Mulligan, Casey B. and Yona Rubinstein, "Selection, Investment, and Women's Relative Wages since 1975," February 2005. NBER Working Paper 11159.

O’Neill, June, "The Gender Wage Gap in Wages, circa 2000," American Economic Review, Papers and Proceedings, May 2003, 93 (2), 309-314.

Pencavel, John, "Labor Supply of Men: A Survey," in Orley Ashenfelter and Richard Layard, eds., Handbook of labor economics, Vol. 1, Amsterdam: North-Holland, 1986, pp. 3-101.

Ruggles, Steven, Matthew Sobek, Trent Alexander, Catherine A. Fitch, Ronald Goeken, Patricia Kelly Hall, Miriam King, and Chad Ronnander, Integrated Public Use Microdata Series: Version 4.0 [Machine-readable 
database]. Minneapolis, MN: Minnesota Population Center [producer and distributor], http://usa.ipums.org/usa/ 2009.

Saint-Paul, G., "Is Labour Rigidity Harming Europes Competitiveness? The Effect of Job Protection on the Pattern of Trade and Welfare," European Economic Review, 1997, 41, 499-506.

Wacziarg, Romain and Jessica Seddon Wallack, "Trade liberalization and Intersectoral Labor Movements," Journal of International Economics, December 2004, 64 (2), 411439.

Welch, Finis, "Growth in Women's Relative Wages and in Inequality Among Men: One Phenomenon or Two?," The American Economic Review, May 2000, 90 (2), 444-449. 


\section{Figures \& Tables}

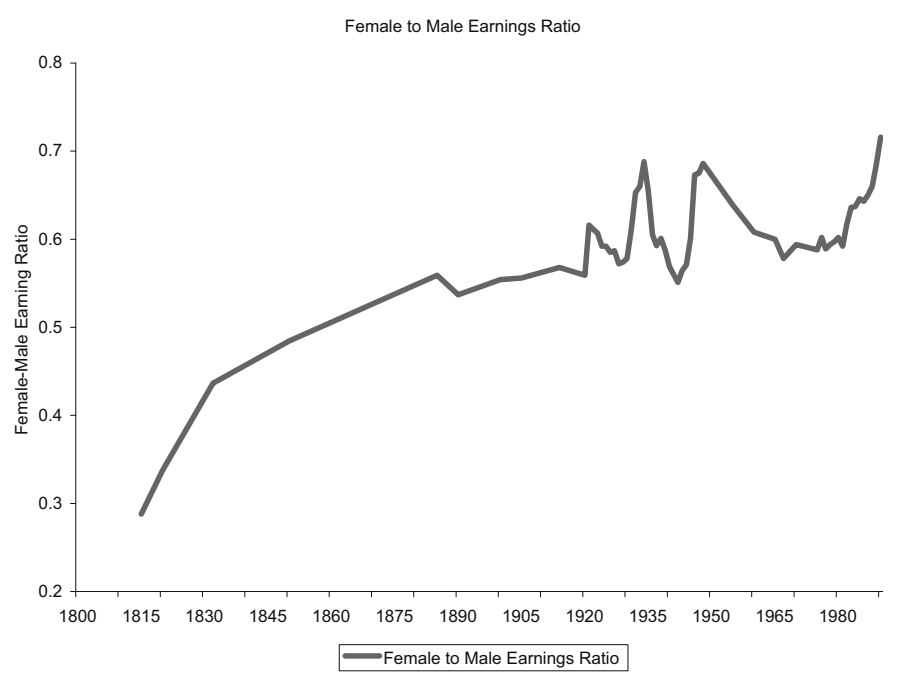

Figure 1: Relative Wages, United States 1800-1990. Source: Galor (2005).
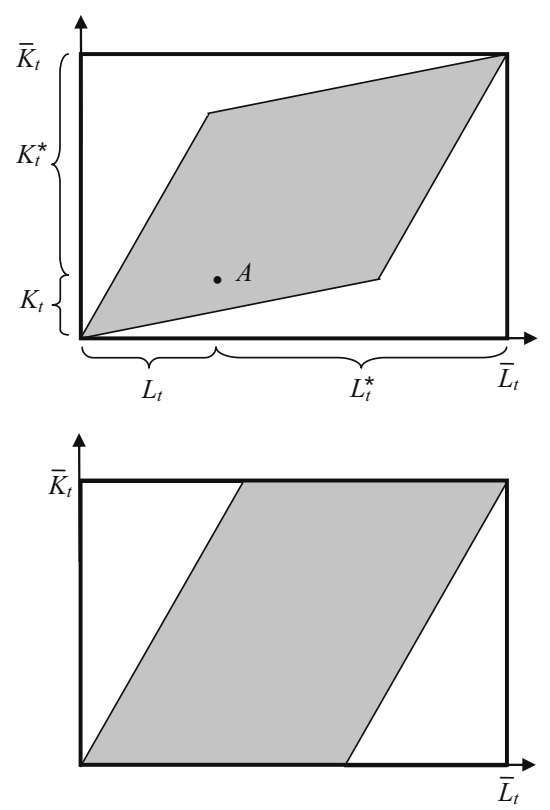

Figure 2: Factor Price Equalization Set 


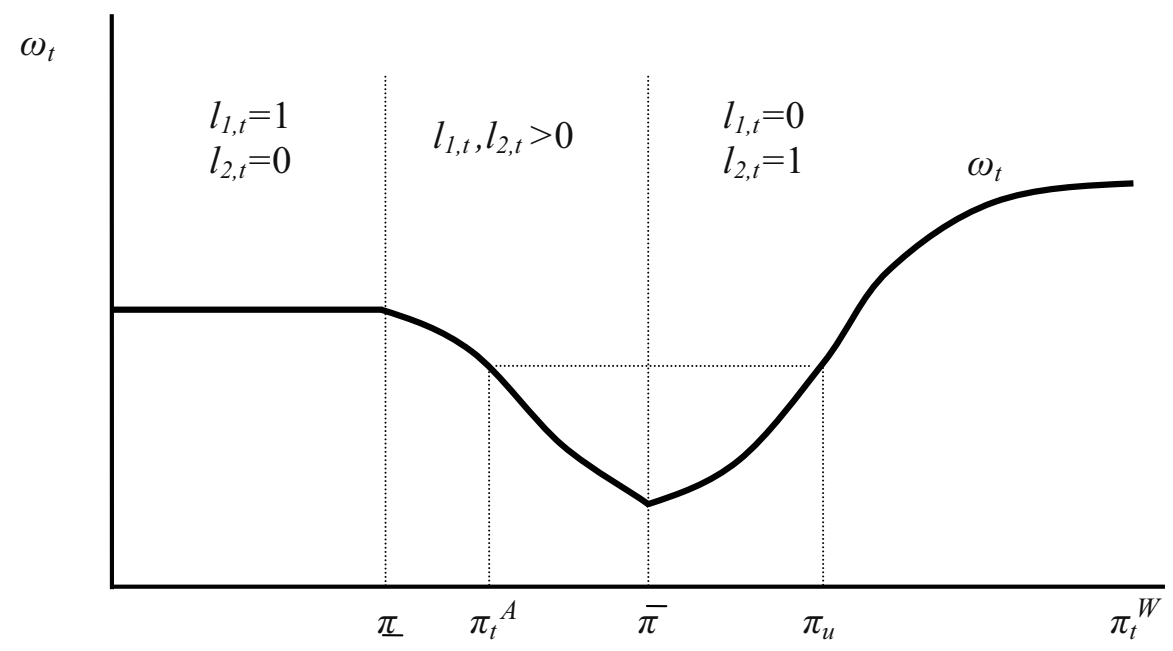

Figure 3: Wage Gap and World Price

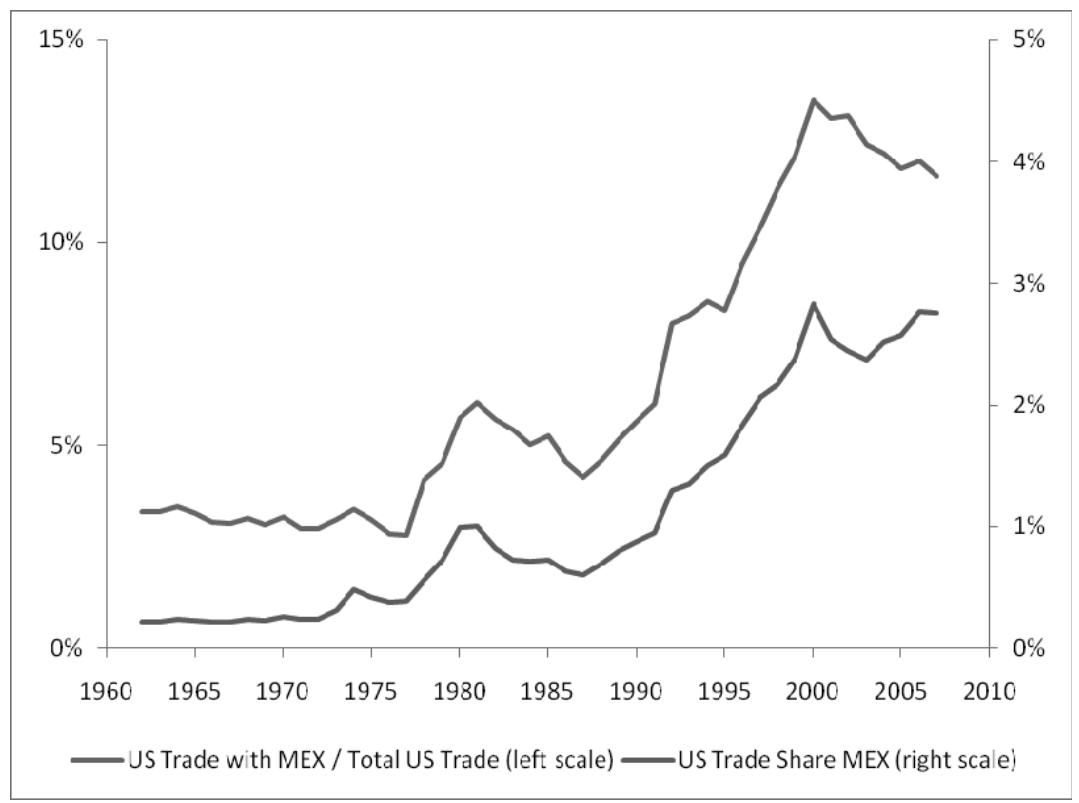

Figure 4: U.S. Trade Share - Imports plus Exports over GDP - with Mexico (red line, right scale) and Mexico's Share of U.S. Trade Volumes (blue line, left scale). Source: (1) Nominal GDP: are from Heston et al. (2006) and (2) US imports from and export to Mexico are from Feenstra et al. (2005) for the period 1962 - 2000 and from United States International Trade Commission for the period $2001-2008$ 


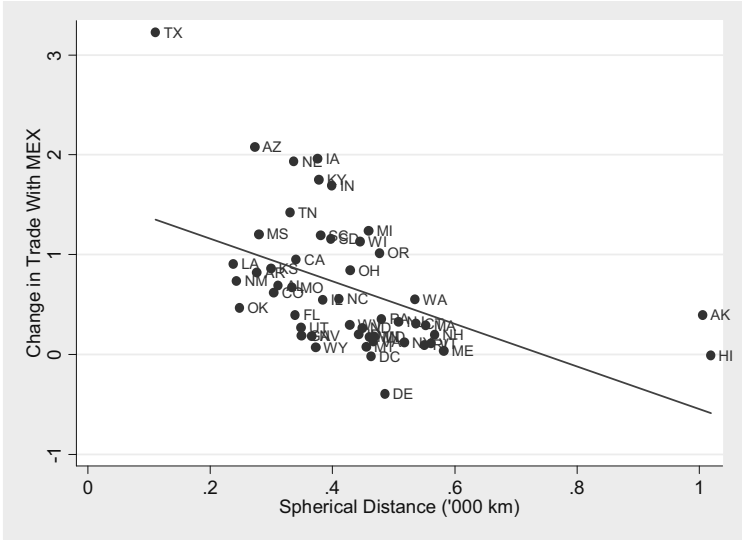

slope $=-2.13$ t-statistic $=-3.92$

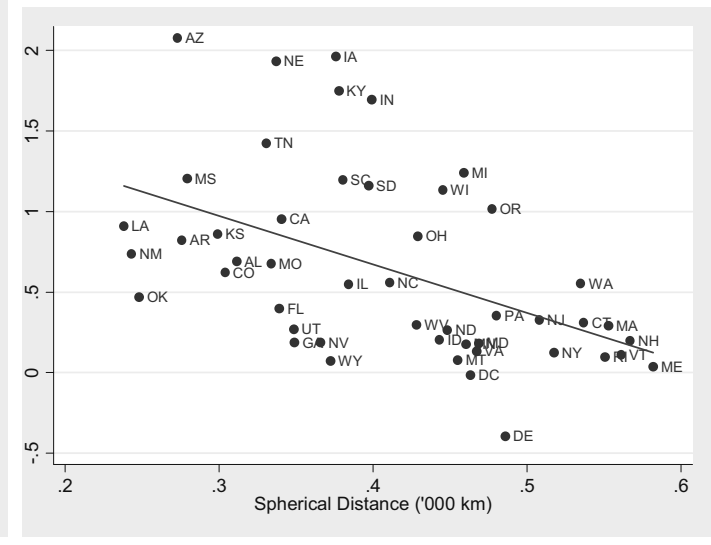

slope $=-3 \quad$ t-statistic $=-3.75$

Figure 5: Change in Trade with Mexico by State (1990-2007). left Panel: all states; right panel: excluding Alaska, Hawaii and Texas. 
Table 1: Characteristics of U.S. State, 1990/91 and 2006/07

\begin{tabular}{|c|c|c|}
\hline \multirow[b]{2}{*}{ FEMALE } & $1990 / 91$ & $2006 / 07$ \\
\hline & \multirow[b]{2}{*}{$\begin{array}{l}39.38 \\
(5.59)\end{array}$} & \multirow[b]{2}{*}{$\begin{array}{l}56.55 \\
(5.36)\end{array}$} \\
\hline Education (\%) & & \\
\hline Weekly hours worked & $\begin{array}{l}22.77 \\
(1.92)\end{array}$ & $\begin{array}{l}24.24 \\
(1.84)\end{array}$ \\
\hline Employment (\%) & $\begin{array}{c}65 \\
(5.2)\end{array}$ & $\begin{array}{c}67 \\
(4.7)\end{array}$ \\
\hline \multicolumn{3}{|l|}{ MALE } \\
\hline Education (\%) & $\begin{array}{l}41.21 \\
(6.36)\end{array}$ & $\begin{array}{l}50.87 \\
(5.92)\end{array}$ \\
\hline Weekly hours worked & $\begin{array}{l}32.92 \\
(1.89)\end{array}$ & $\begin{array}{l}32.2 \\
(1.81)\end{array}$ \\
\hline Employment (\%) & $\begin{array}{l}78 \\
(3.6)\end{array}$ & $\begin{array}{c}77 \\
(4.2)\end{array}$ \\
\hline \multicolumn{3}{|l|}{ State } \\
\hline per-capita GSP & $\begin{array}{c}28321 \\
(11307)\end{array}$ & $\begin{array}{l}37968 \\
(13881)\end{array}$ \\
\hline Trade share (\%) & $\begin{array}{c}0.53 \\
(0.98)\end{array}$ & $\begin{array}{l}1.21 \\
(1.51)\end{array}$ \\
\hline Unemployment (\%) & $\begin{array}{l}6.34 \\
(1.36)\end{array}$ & $\begin{array}{c}4.82 \\
(1.09)\end{array}$ \\
\hline Mexican Immigrants (\%) & $\begin{array}{l}1.47 \\
(3.03)\end{array}$ & $\begin{array}{c}2.94 \\
(3.69)\end{array}$ \\
\hline
\end{tabular}

Note.-Gross state standard deviations are in parentheses. Data for education, labor participation and Mexican immigrants are from IPUMS-CPS, data for trade are from World Institute for Strategic Economic Research and data for Gross State Product are from the Bureau of Economic Analysis. State Education rate is measured by the share of civilians aged 1665 that have, at least, some college. Employment is the share of the working group out of the population aged 16-65. Per capita Gross State Product data are chained 2000 dollars. Trade share data are calculated as two fold export volumes over GSP. Census sample weights are used for all calculations. 


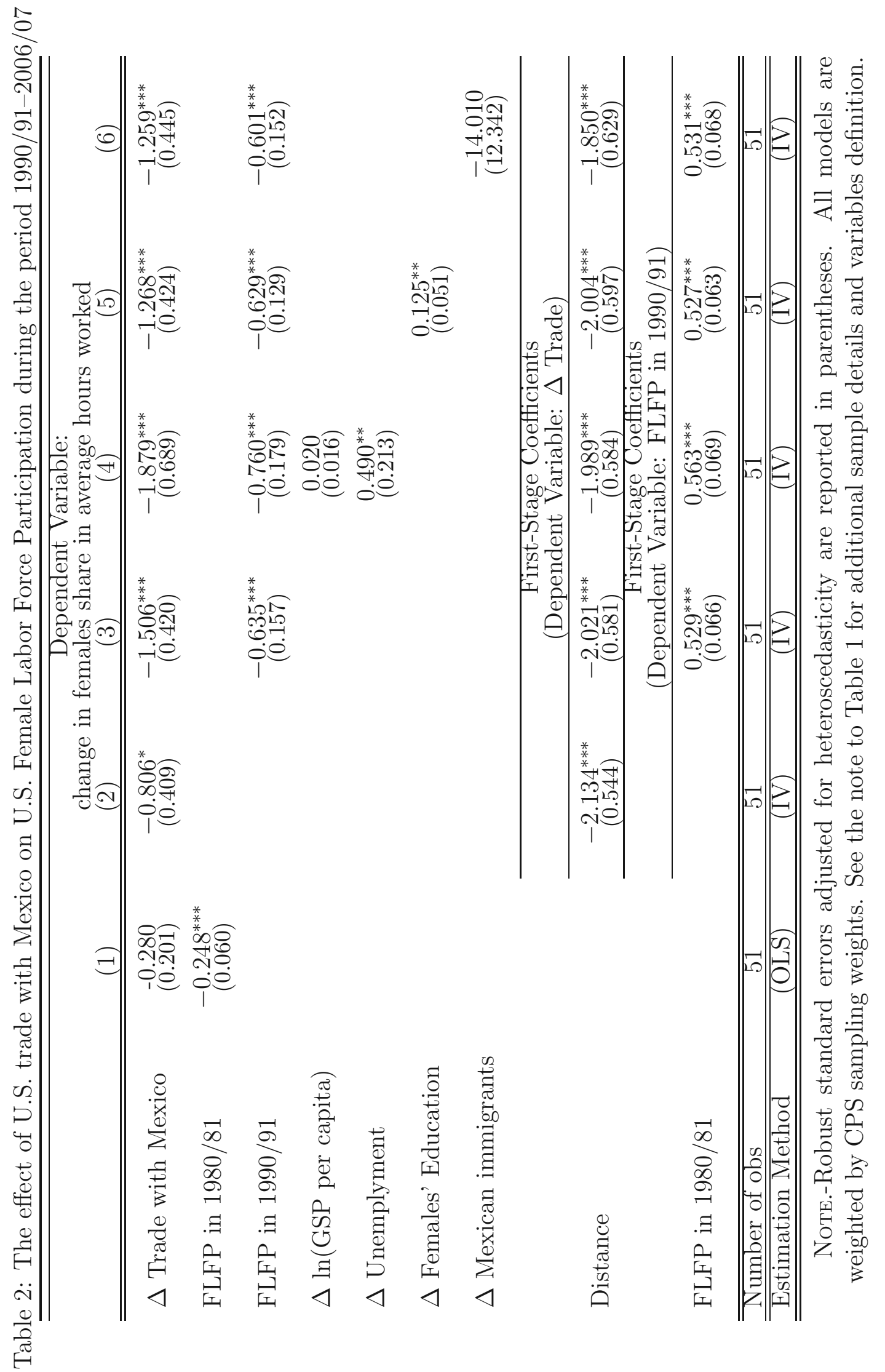




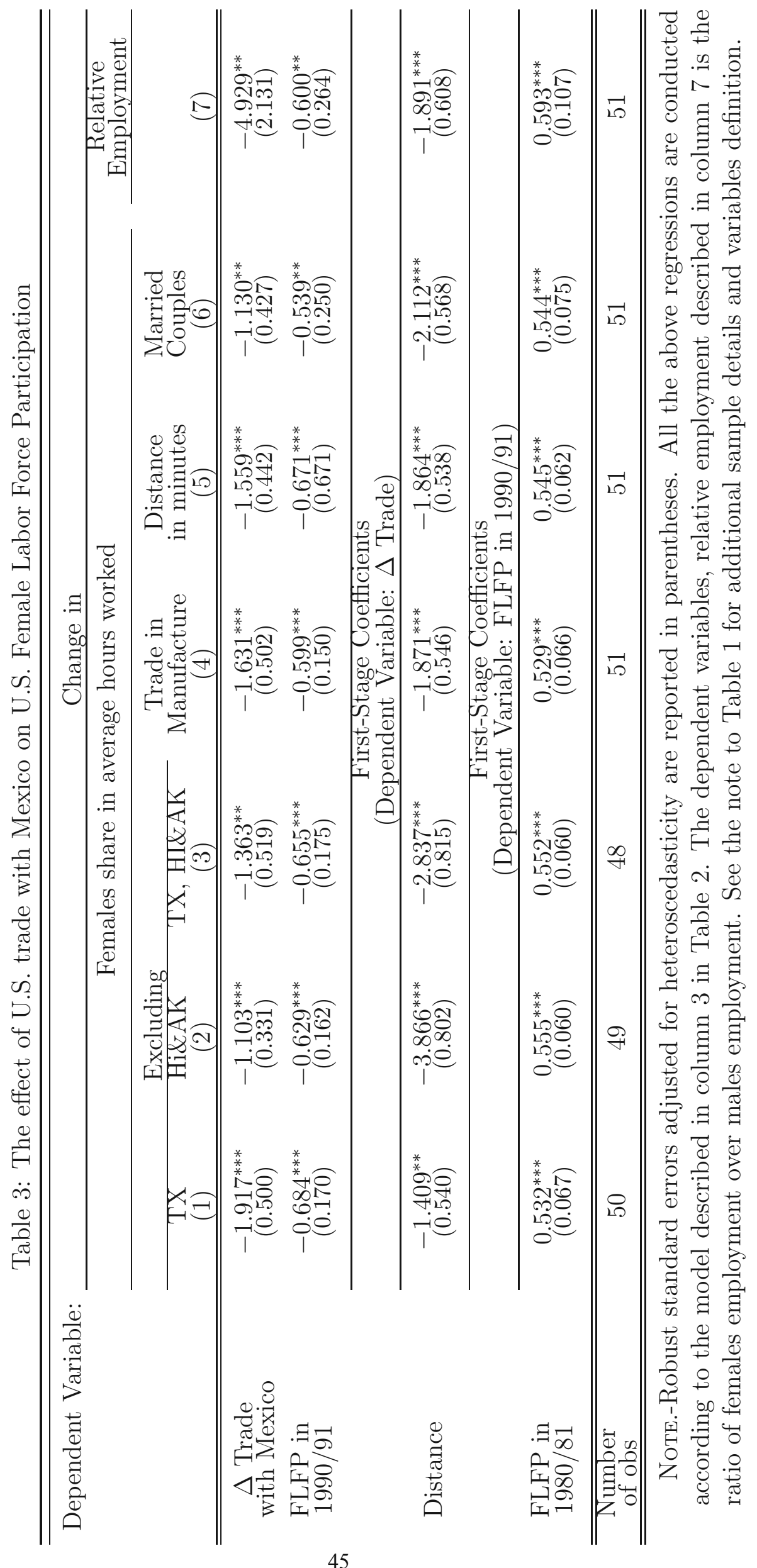




\section{APPENDIX}

\section{Proofs \& Tables}

Proof that $1 / m_{t}$ is bounded above. First observe that $k_{t} \rightarrow \infty$ means $k_{t}>k_{o}$ so that the second regime applies. Use (23) to confirm that $\kappa_{t} \rightarrow \infty$ as $k_{t} \rightarrow \infty$ (else the denominator in the brackets of the expression on the right turns negative). Finally, divide equation (21) by $\kappa_{t}^{\alpha}$ to get

$$
\frac{1-\theta}{\theta} \frac{1}{\kappa_{t}^{\alpha \rho}}\left(\frac{\frac{a}{b} m_{t}+\left[m_{t}-\left(1-z n_{t}\right)\right] \kappa_{t}^{-\alpha}}{1-m_{t}+\left(1-z n_{t}\right)}\right)^{1-\rho} \rightarrow(1-\alpha) \frac{a}{b} \quad\left(k_{t} \rightarrow \infty\right)
$$

Since this limit is positive, the term in brackets must approach infinity as $k_{t} \rightarrow \infty$ so that, as $\lim _{\kappa_{t} \rightarrow \infty} z n_{t}=2 \gamma, \lim _{k_{t} \rightarrow \infty} m_{t}=2(1-\gamma)$ must hold. This proves that $1 / m_{t}$ is bounded above.

Proof of Proposition 1. The proof of " $\Rightarrow$ " is immediate by $r_{t}=r_{t}^{*}$ and (9).

For " $\Leftarrow "$ assume that $\kappa_{t}^{*}=\kappa_{t}$, which implies $r_{t}=p_{1, t} \alpha a \kappa_{t}^{\alpha-1}=p_{1, t} \alpha a\left(\kappa_{t}^{*}\right)^{\alpha-1}=r_{t}^{*}$ and $w_{t}^{F}=p_{1, t}(1-\alpha) a \kappa_{t}^{\alpha}=p_{1, t}(1-\alpha) a\left(\kappa_{t}^{*}\right)^{\alpha}=w_{t}^{F, *}$. By $X_{2, t}>0$ we have $l_{2, t}+l_{2, t}^{*}>0$. In case $l_{2, t}^{*}, l_{2, t}>0 w_{t}^{M}=w_{t}^{M, *}$ follows from (10). In case $l_{2, t}^{*}=0$ this implies

$$
w_{t}^{M}=p_{2, t} b \leq w_{t}^{M, *}
$$

At the same time $l_{1, t}^{*}=1$ implies

$$
w_{t}^{M, *}=p_{1, t}\left((1-\alpha) a\left(\kappa_{t}^{*}\right)^{\alpha}+b\right)=p_{1, t}\left((1-\alpha) a \kappa_{t}^{\alpha}+b\right) \leq w_{t}^{M}
$$

so that $w_{t}^{M}=w_{t}^{M, *}$. In case $l_{2, t}=0$ switching Home and Foreign variables leads to $w_{t}^{M}=$ $w_{t}^{M, *}$ again. 
Proof of Proposition 3. (i) By (15) it is sufficient to show $\omega_{t}^{*} \leq \omega_{t}$. Since free trade implies $l_{1, t}^{*}>0$ and $l_{2, t}>0$ we have $\omega_{t}=\pi_{t} b /\left[a(1-\alpha) \kappa_{t}^{\alpha}\right] \geq 1+b /\left[a(1-\alpha) \kappa_{t}^{\alpha}\right]$ and $\omega_{t}^{*}=1+b /\left[a(1-\alpha)\left(\kappa_{t}^{*}\right)^{\alpha}\right] \geq \pi_{t} b /\left[a(1-\alpha)\left(\kappa_{t}^{*}\right)^{\alpha}\right]$. Combining these relations gives

$$
\frac{\omega_{t}^{*}}{\omega_{t}} \leq \frac{\pi_{t}+\omega_{t}^{*}}{\pi_{t}+\omega_{t}}
$$

and proves statement (i).

(ii) By (i) and (15) we have $z n_{t}^{*} \leq z n_{t}$ and can distinguish two cases. The first where $z n_{t}=1$ gives with (39) and $l_{2, t}>0$

$$
\frac{k_{t+1}^{*}}{k_{t+1}} \geq \frac{w^{M, *}}{w^{M}} \geq \frac{p_{2, t} b}{p_{2, t} b}=1
$$

If instead $z n_{t}<1$ (i) implies $z n_{t}^{*}<1$ so that (39)

$$
\frac{k_{t+1}^{*}}{k_{t+1}}=\frac{w^{F, *}}{w^{F}}=\frac{\omega_{t}}{\omega_{t}^{*}} \frac{w^{M, *}}{w^{M}} \geq \frac{w^{M, *}}{w^{M}}=1
$$

where we used (i) in the first inequality and the second inequality follows as above.

(iii) If $z n_{t}^{A}=1$ we have

$$
\frac{k_{t+1}^{A}}{k_{t+1}} \leq \frac{w^{M, A}}{w^{M}}=\frac{p_{2, t}^{A} b}{p_{2, t} b} \leq 1
$$

If, instead, $z n_{t}^{A}<1$ then $z n_{t}<1$ (from (35) as long as $l_{1, t}>0$ and $m_{t}>0$ otherwise) and

$$
\frac{k_{t+1}^{A}}{k_{t+1}} \leq \frac{w^{F, A}}{w^{F}}=\frac{\omega_{t}}{\omega_{t}^{A}} \frac{w^{M, A}}{w^{M}}
$$

For the case $\omega_{t} \leq \omega_{t}^{A}$ (or $\pi_{t} \leq \pi_{u}$ in Figure 3) this proves the claim. If instead $\omega_{t}>\omega_{t}^{A}$ we use $\kappa_{t}=k_{t} /\left(1-z n_{t}\right)$ and $(15)$ to write

$$
\kappa_{t}\left(1-\gamma\left(1+\pi_{t} \frac{b / a}{1-\alpha} \kappa_{t}^{-\alpha}\right)\right)=k_{t}
$$


and take implicit derivatives

$$
\frac{d \kappa_{t}}{d \pi_{t}}=\kappa_{t} \frac{1}{1-\alpha} \frac{\gamma}{(1-\gamma) a / b \kappa_{t}^{\alpha}-\gamma \pi_{t}}
$$

At the same time (40) leads to

$$
\frac{d p_{1, t}}{d \pi_{t}}=-p_{1, t}^{1-\frac{\rho}{1-\rho}}\left(\frac{1-\theta}{\pi_{t}}\right)^{\frac{1}{1-\rho}}
$$

Thus,

$$
\frac{d}{d \pi_{t}} \ln \left(p_{1, t} \kappa_{t}^{\alpha}\right)=\frac{\alpha}{1-\alpha} \frac{\gamma}{(1-\gamma) a / b \kappa_{t}^{\alpha}-\gamma \pi_{t}}-\left(\left(\frac{\theta}{1-\theta}\right)^{\frac{1}{1-\rho}} \pi_{t}^{\frac{\rho}{1-\rho}}+\pi_{t}^{\frac{-\rho}{1-\rho}}\right)^{-1} \pi_{t}^{-1}
$$

A sufficient condition for this expression to be positive is

$$
\frac{\alpha}{1-\alpha} \frac{\gamma}{\pi_{t}^{-1}(1-\gamma) a / b \kappa_{t}^{\alpha}-\gamma}>\frac{1}{\left(\frac{\theta}{1-\theta}\right)^{\frac{1}{1-\rho}} \pi_{t}^{\frac{\rho}{1-\rho}}+1}
$$

or with $\omega_{t}=\pi_{t} b /\left[a(1-\alpha) \kappa_{t}^{\alpha}\right]$

$$
\frac{\alpha}{1-\alpha} \frac{\gamma}{\frac{1-\gamma}{1-\alpha} \frac{1}{\omega_{t}}-\gamma}>\frac{1}{\left(\frac{\theta}{1-\theta}\right)^{\frac{1}{1-\rho}} \pi_{t}^{\frac{\rho}{1-\rho}}+1}
$$

Since $\omega_{t}>1$ and $\pi_{t}>1$ this condition is satisfied whenever

$$
\alpha \frac{\gamma}{1-\gamma-(1-\alpha) \gamma}>\frac{1}{\left(\frac{\theta}{1-\theta}\right)^{\frac{1}{1-\rho}}+1}
$$

or $(\theta /(1-\theta))^{\frac{1}{1-\rho}} \geq(1-2 \gamma) /(\alpha \gamma)$ holds, proving the statement (iii).

(iv) Notice with Proposition 2 (i) that $z n_{t}^{*}<1$ implies $k_{t+1}^{*} / k_{t+1}^{*, A}=p_{1, t}\left(\kappa_{t}^{*}\right)^{\alpha} /\left(p_{1, t}^{*, A}\left(\kappa_{t}^{*, A}\right)^{\alpha}\right)$. If $z n_{t}^{*}=1$, instead, $k_{t+1}^{*} / k_{t+1}^{*, A}=p_{1, t}\left((1-\alpha) a \kappa_{t}^{*}+b\right) /\left(p_{1, t}^{*, A}\left((1-\alpha) a \kappa_{t}^{*, A}+b\right)\right)$. Now, inequality (37) and expression (40) for the price $p_{1, t}^{(*, A)}$ imply $p_{1, t} / p_{1, t}^{*, A} \leq 1$. Further, by $m_{t}^{*, A} \leq m_{t}^{*}$ we 
have $\kappa_{t}^{*, A} \geq \kappa_{t}^{*}$ and thus

$$
k_{t+1}^{*} / k_{t+1}^{*, A} \leq\left(\kappa_{t}^{*} / \kappa_{t}^{*, A}\right)^{\alpha}
$$

Similarly, we compute for $z n_{t}<1$ that $k_{t+1} / k_{t+1}^{A}=p_{1, t} \kappa_{t}^{\alpha} /\left(p_{1, t}^{A}\left(\kappa_{t}^{A}\right)^{\alpha}\right)$ while for $z n_{t}=1$ $k_{t+1} / k_{t+1}^{A}=p_{1, t}\left((1-\alpha) a \kappa_{t}^{\alpha}+b\right) /\left(p_{1, t}^{A}\left((1-\alpha) a\left(\kappa_{t}^{A}\right)^{\alpha}+b\right)\right)$ holds. By (37) and expression (40) we have $p_{1, t} / p_{1, t}^{A} \geq 1$. Further, by $m_{t}^{A} \geq m_{t}$ we have $\kappa_{t}^{A} \geq \kappa_{t}$ and thus

$$
k_{t+1} / k_{t+1}^{A} \geq\left(\kappa_{t} / \kappa_{t}^{A}\right)^{\alpha}
$$

Combining both inequalities leads to

$$
\frac{k_{t+1}^{*} / k_{t+1}^{*, A}}{k_{t+1} / k_{t+1}^{A}} \leq\left(\frac{\kappa_{t}^{*} / \kappa_{t}^{*, A}}{\kappa_{t} / \kappa_{t}^{A}}\right)^{\alpha}=\left(\frac{m_{t}^{*, A} / m_{t}^{*}}{m_{t}^{A} / m_{t}}\right)^{\alpha}
$$

Using again $m_{t}^{*, A} \leq m_{t}^{*}$ and $m_{t}^{A} \geq m_{t}$ shows that the expression on the right falls weakly short of unitiy, which proves the statement. 
Table A-1: Explanatory Power of Distance on Female Labor Force Participation

\begin{tabular}{|c|c|c|c|c|}
\hline \multirow[t]{3}{*}{ Dependent Variable: } & \multicolumn{2}{|c|}{$\begin{array}{l}\text { Share of } \\
\text { Hours Worked }\end{array}$} & \multicolumn{2}{|c|}{$\begin{array}{c}\text { Relative } \\
\text { Employment } \\
\end{array}$} \\
\hline & $\begin{array}{l}\text { before } \\
\text { NAFTA }\end{array}$ & $\begin{array}{l}\text { during } \\
\text { NAFTA }\end{array}$ & $\begin{array}{l}\text { before } \\
\text { NAFTA }\end{array}$ & $\begin{array}{l}\text { during } \\
\text { NAFTA }\end{array}$ \\
\hline & $(1)$ & $(2)$ & $(3)$ & (4) \\
\hline distance & $\begin{array}{l}-3.933^{* * *} \\
(1.44)\end{array}$ & $\begin{array}{l}2.703^{* * *} \\
(0.562)\end{array}$ & $\begin{array}{l}-4.423 \\
(4.572)\end{array}$ & $\begin{array}{l}10.236^{* * *} \\
(1.844)\end{array}$ \\
\hline \multirow[t]{2}{*}{ Initial FLFP } & $\begin{array}{l}-0.009 \\
(0.111)\end{array}$ & $\begin{array}{c}-0.544^{* * *} \\
(0.08)\end{array}$ & -0.217 & $\begin{array}{l}-0.736^{* * *} \\
(0.125)\end{array}$ \\
\hline & \multicolumn{4}{|c|}{$\begin{array}{c}\text { First-Stage Coefticients } \\
\text { (Dependent Variable: Initial level for FLFP) }\end{array}$} \\
\hline Lagged FLFP & $\begin{array}{c}0.675^{* * *} \\
(0.085)\end{array}$ & $\begin{array}{c}0.593^{* * *} \\
(0.039)\end{array}$ & $\begin{array}{c}0.753^{* * *} \\
(0.047)\end{array}$ & $\begin{array}{c}0.632^{* * *} \\
(0.068)\end{array}$ \\
\hline Number of obs & $\overline{42}$ & 51 & 42 & 51 \\
\hline \multicolumn{5}{|c|}{$\begin{array}{l}\text { NotE.-Robust standard errors adjusted for heteroscedasticity are reported in paren } \\
\text { theses. In all regressions the variable Female Labor Force Participation is regressed or } \\
\text { distance and the initial level of FLFP. The dependent variables, relative employment } \\
\text { described in columns } 3 \& 4 \text { is the ratio of females employment over males employment } \\
\text { The initial level of FLFP is instrumented by its lagged level. The before NAFTA pe } \\
\text { riod is } 1960-1970 \text { and the during NAFTA period is 1990-2000. Lagged levels are } 1950 \\
\text { and } 1980 \text {, respectively. For the before NAFTA period part of the data are missing } \\
\text { for } 9 \text { states, which are Alaska, Delaware, Hawaii, Idaho, Montana, North Dakota } \\
\text { South Dakota, Vermont and Wyoming. restricting our during NAFTA period regres } \\
\text { sions to the same } 42 \text { states does not affect neither the magnitudes of coefficients no } \\
\text { its significance. See the note to Table } 1 \text { for additional sample details and variable } \\
\text { definition. }\end{array}$} \\
\hline
\end{tabular}




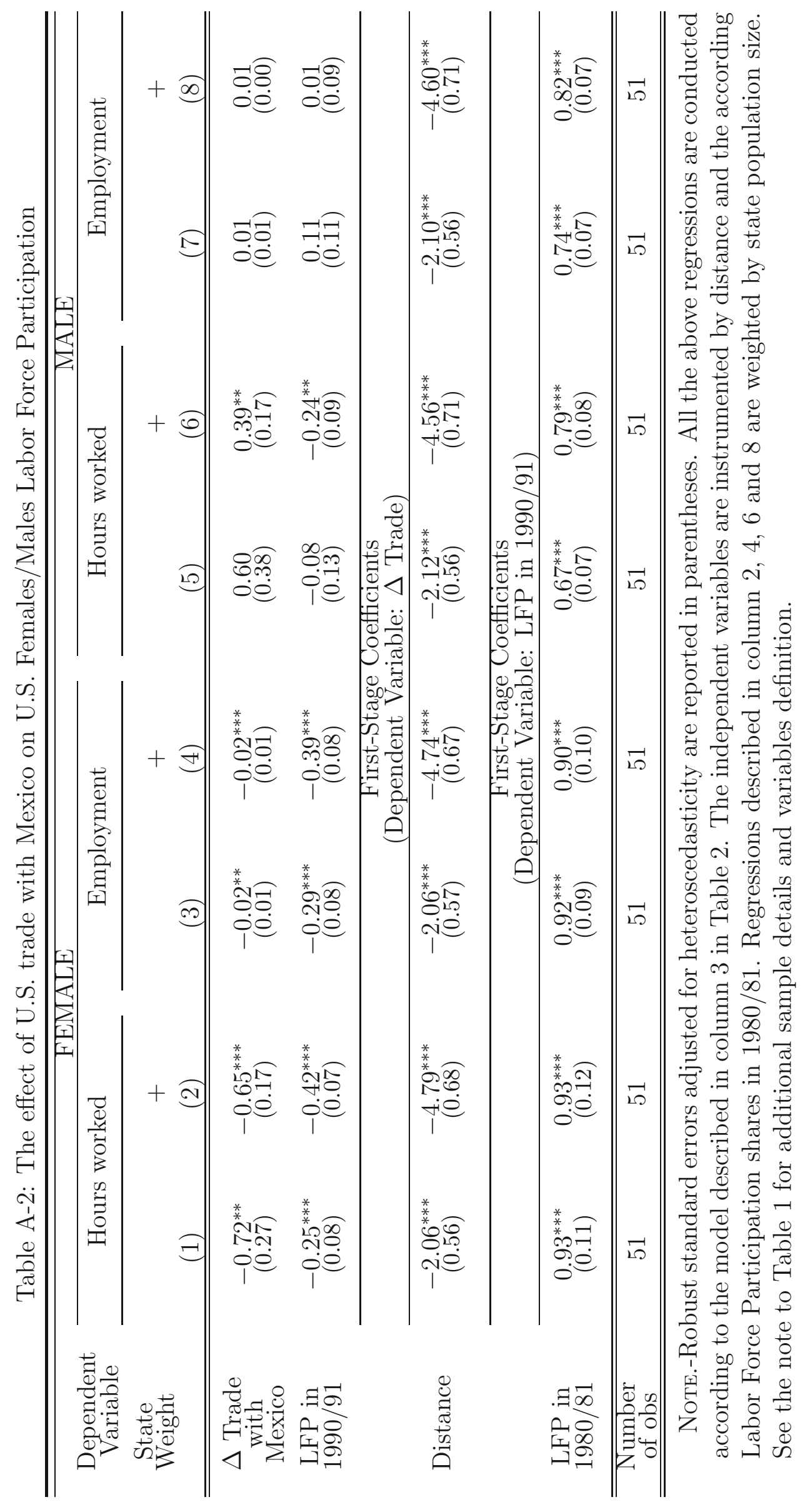




\section{Swiss National Bank Working Papers published since 2004:}

2004-1 Samuel Reynard: Financial Market Participation and the Apparent Instability of Money Demand

2004-2 Urs W. Birchler and Diana Hancock: What Does the Yield on Subordinated Bank Debt Measure?

2005-1 Hasan Bakhshi, Hashmat Khan and Barbara Rudolf: The Phillips curve under state-dependent pricing

2005-2 Andreas M. Fischer: On the Inadequacy of Newswire Reports for Empirical Research on Foreign Exchange Interventions

2006-1 Andreas M. Fischer: Measuring Income Elasticity for Swiss Money Demand: What do the Cantons say about Financial Innovation?

2006-2 Charlotte Christiansen and Angelo Ranaldo: Realized Bond-Stock Correlation: Macroeconomic Announcement Effects

2006-3 Martin Brown and Christian Zehnder: Credit Reporting, Relationship Banking, and Loan Repayment

2006-4 Hansjörg Lehmann and Michael Manz: The Exposure of Swiss Banks to Macroeconomic Shocks - an Empirical Investigation

2006-5 Katrin Assenmacher-Wesche and Stefan Gerlach: Money Growth, Output Gaps and Inflation at Low and High Frequency: Spectral Estimates for Switzerland

2006-6 Marlene Amstad and Andreas M. Fischer: Time-Varying Pass-Through from Import Prices to Consumer Prices: Evidence from an Event Study with Real-Time Data

2006-7 Samuel Reynard: Money and the Great Disinflation

2006-8 Urs W. Birchler and Matteo Facchinetti: Can bank supervisors rely on market data? A critical assessment from a Swiss perspective

2006-9 Petra Gerlach-Kristen: A Two-Pillar Phillips Curve for Switzerland

2006-10 Kevin J. Fox and Mathias Zurlinden: On Understanding Sources of Growth and Output Gaps for Switzerland

2006-11 Angelo Ranaldo: Intraday Market Dynamics Around Public Information Arrivals

2007-1 Andreas M. Fischer, Gulzina Isakova and Ulan Termechikov: Do FX traders in Bishkek have similar perceptions to their London colleagues? Survey evidence of market practitioners' views 
2007-2 Ibrahim Chowdhury and Andreas Schabert: Federal Reserve Policy viewed through a Money Supply Lens

2007-3 Angelo Ranaldo: Segmentation and Time-of-Day Patterns in Foreign Exchange Markets

2007-4 Jürg M. Blum: Why ‘Basel II’ May Need a Leverage Ratio Restriction

2007-5 Samuel Reynard: Maintaining Low Inflation: Money, Interest Rates, and Policy Stance

2007-6 Rina Rosenblatt-Wisch: Loss Aversion in Aggregate Macroeconomic Time Series

2007-7 Martin Brown, Maria Rueda Maurer, Tamara Pak and Nurlanbek Tynaev: Banking Sector Reform and Interest Rates in Transition Economies: Bank-Level Evidence from Kyrgyzstan

2007-8 Hans-Jürg Büttler: An Orthogonal Polynomial Approach to Estimate the Term Structure of Interest Rates

2007-9 Raphael Auer: The Colonial Origins Of Comparative Development: Comment. A Solution to the Settler Mortality Debate

2007-10 Franziska Bignasca and Enzo Rossi: Applying the Hirose-Kamada filter to Swiss data: Output gap and exchange rate pass-through estimates

2007-11 Angelo Ranaldo and Enzo Rossi: The reaction of asset markets to Swiss National Bank communication

2007-12 Lukas Burkhard and Andreas M. Fischer: Communicating Policy Options at the Zero Bound

2007-13 Katrin Assenmacher-Wesche, Stefan Gerlach, and Toshitaka Sekine: Monetary Factors and Inflation in Japan

2007-14 Jean-Marc Natal and Nicolas Stoffels: Globalization, markups and the natural rate of interest

2007-15 Martin Brown, Tullio Jappelli and Marco Pagano: Information Sharing and Credit: Firm-Level Evidence from Transition Countries

2007-16 Andreas M. Fischer, Matthias Lutz and Manuel Wälti: Who Prices Locally? Survey Evidence of Swiss Exporters

2007-17 Angelo Ranaldo and Paul Söderlind: Safe Haven Currencies 
2008-1 Martin Brown and Christian Zehnder: The Emergence of Information Sharing in Credit Markets

2008-2 Yvan Lengwiler and Carlos Lenz: Intelligible Factors for the Yield Curve

2008-3 Katrin Assenmacher-Wesche and M. Hashem Pesaran: Forecasting the Swiss Economy Using VECX* Models: An Exercise in Forecast Combination Across Models and Observation Windows

2008-4 Maria Clara Rueda Maurer: Foreign bank entry, institutional development and credit access: firm-level evidence from 22 transition countries

2008-5 Marlene Amstad and Andreas M. Fischer: Are Weekly Inflation Forecasts Informative?

2008-6 Raphael Auer and Thomas Chaney: Cost Pass Through in a Competitive Model of Pricing-to-Market

2008-7 Martin Brown, Armin Falk and Ernst Fehr: Competition and Relational Contracts: The Role of Unemployment as a Disciplinary Device

2008-8 Raphael Auer: The Colonial and Geographic Origins of Comparative Development

2008-9 Andreas M. Fischer and Angelo Ranaldo: Does FOMC News Increase Global FX Trading?

2008-10 Charlotte Christiansen and Angelo Ranaldo: Extreme Coexceedances in New EU Member States' Stock Markets

2008-11 Barbara Rudolf and Mathias Zurlinden: Measuring capital stocks and capital services in Switzerland

2008-12 Philip Sauré: How to Use Industrial Policy to Sustain Trade Agreements

2008-13 Thomas Bolli and Mathias Zurlinden: Measuring growth of labour quality and the quality-adjusted unemployment rate in Switzerland

2008-14 Samuel Reynard: What Drives the Swiss Franc?

2008-15 Daniel Kaufmann: Price-Setting Behaviour in Switzerland - Evidence from CPI Micro Data

2008-16 Katrin Assenmacher-Wesche and Stefan Gerlach: Financial Structure and the Impact of Monetary Policy on Asset Prices

2008-17 Ernst Fehr, Martin Brown and Christian Zehnder: On Reputation: A Microfoundation of Contract Enforcement and Price Rigidity 
2008-18 Raphael Auer and Andreas M. Fischer: The Effect of Low-Wage Import Competition on U.S. Inflationary Pressure

2008-19 Christian Beer, Steven Ongena and Marcel Peter: Borrowing in Foreign Currency: Austrian Households as Carry Traders

2009-1 Thomas Bolli and Mathias Zurlinden: Measurement of labor quality growth caused by unobservable characteristics

2009-2 Martin Brown, Steven Ongena and Pinar Yeșin: Foreign Currency Borrowing by Small Firms

2009-3 Matteo Bonato, Massimiliano Caporin and Angelo Ranaldo: Forecasting realized (co)variances with a block structure Wishart autoregressive model

2009-4 Paul Söderlind: Inflation Risk Premia and Survey Evidence on Macroeconomic Uncertainty

2009-5 Christian Hott: Explaining House Price Fluctuations

2009-6 Sarah M. Lein and Eva Köberl: Capacity Utilisation, Constraints and Price Adjustments under the Microscope

2009-7 Philipp Haene and Andy Sturm: Optimal Central Counterparty Risk Management

2009-8 Christian Hott: Banks and Real Estate Prices

2009-9 Terhi Jokipii and Alistair Milne: Bank Capital Buffer and Risk Adjustment Decisions

2009-10 Philip Sauré: Bounded Love of Variety and Patterns of Trade

2009-11 Nicole Allenspach: Banking and Transparency: Is More Information Always Better?

2009-12 Philip Sauré and Hosny Zoabi: Effects of Trade on Female Labor Force Participation 
Swiss National Bank Working Papers are also available at www.snb.ch, section Publications/Research Subscriptions or individual issues can be ordered at Swiss National Bank, Fraumünsterstrasse 8, CH-8022 Zurich, fax+41 4463181 14, E-mail library@snb.ch 